
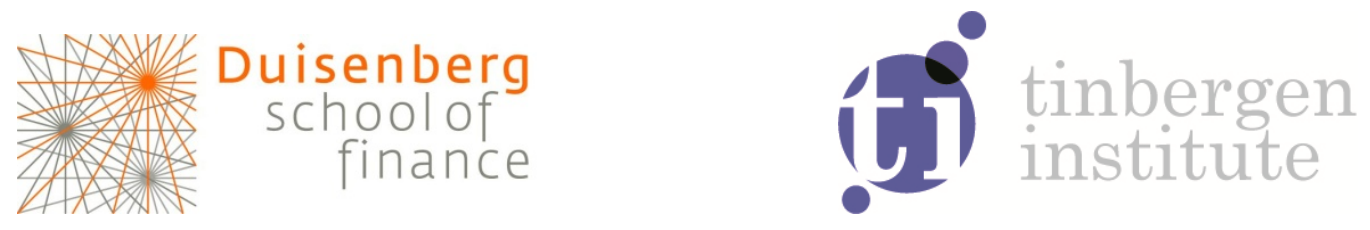

Duisenberg school of finance - Tinbergen Institute Discussion Paper

TI 14-035 /VI/ DSF 74

\title{
Shadow Banking and Traditional Bank Lending: \\ The Role of Implicit Guarantees
}

Lucyna Gornicka 
Tinbergen Institute is the graduate school and research institute in economics of Erasmus University Rotterdam, the University of Amsterdam and VU University Amsterdam.

More TI discussion papers can be downloaded at http://www.tinbergen.nl

Tinbergen Institute has two locations:

Tinbergen Institute Amsterdam

Gustav Mahlerplein 117

1082 MS Amsterdam

The Netherlands

Tel.: +31(0)205251600

Tinbergen Institute Rotterdam

Burg. Oudlaan 50

3062 PA Rotterdam

The Netherlands

Tel.: +31(0)10 4088900

Fax: +31(0)104089031

Duisenberg school of finance is a collaboration of the Dutch financial sector and universities, with the ambition to support innovative research and offer top quality academic education in core areas of finance.

DSF research papers can be downloaded at: http://www.dsf.nl/

Duisenberg school of finance

Gustav Mahlerplein 117

1082 MS Amsterdam

The Netherlands

Tel.: +31(0)20 5258579 


\title{
Shadow banking and traditional bank lending: the role of implicit guarantees*
}

\author{
Lucyna A. Górnicka ${ }^{\dagger}$
}

First version: September 2013

This version: June 16, 2014

\begin{abstract}
Bank holding companies invest in risky projects through bank entities or sell projects for a fee, thus engaging in shadow banking. To increase the fee income, BHCs guarantee sold projects with bank proceeds. For high capital requirements and for high demand for financial assets, BHCs expand their bank investments to increase the value of guarantees and to raise demand for off-balance intermediation. The amount of credit in the economy increases, bank defaults are more frequent, and costs of deposit insurance increase. For high social costs of interventions, the welfare-maximizing minimum capital requirement lies below the level optimal in absence of shadow banking.
\end{abstract}

Keywords: shadow banking, special purpose vehicles, regulatory arbitrage

JEL Codes: G21, G23, G28

*I have greatly benefited from discussions with my supervisor Sweder van Wijnbergen. I thank Enrico Perotti, Thorsten V. Koeppl, José-Luis Peydró, Marius A. Zoican, Timotej Homar, Swapnil Singh, Stephanie Chan and Simas Kucinskas for comments and suggestions.

${ }^{\dagger} \mathrm{PhD}$ candidate, University of Amsterdam and Tinbergen Institute. Email: l.a.gornicka@uva.nl. Website: sites.google.com/site/lucygornicka/. 


\section{Introduction}

The frequent use of off-balance special purpose vehicles (SPVs) by financial intermediaries is a well-documented empirical fact (Gorton and Metrick (2012)). SPVs are legal entities created with the sole purpose of executing assigned transactions, such as loan sales. They make no own decisions, have no employees, and in most cases are legally independent from the sponsoring institution. Thanks to their legal status, SPVs enjoy special accounting and regulatory treatment: they are bankruptcy-remote (SPV assets cannot be seized in the bankruptcy procedure in case of the sponsor's default) and are not subject to minimum capital requirements.

Importantly, institutions sponsoring SPVs often secure investors' returns through formal or informal guarantees. The guarantees effectively provide a recourse to sponsor's assets if the conduit's loan portfolio performs poorly. Although often non-contractible, the guarantees were realized in the vast majority of cases when the recent financial crisis hit. ${ }^{1}$

This paper investigates potential consequences of granting implicit guarantees by financial intermediaries and explains how the guarantees can be related to several empirical facts about the pre-crisis shadow banking activities:

(I) High demand for riskless assets. With the regulatory cap on deposit insurance $(\$ 100$, 000 in the U.S. before October 2008), the shadow banking sector was a provider of additional supply of safe assets to investors.

(II) Positive relationship between off-balance lending and bank lending capacity. Banks sponsoring off-balance conduits had a tendency to increase their own leverage in comparison to non-sponsor intermediaries (Altunbas, Gambacorta, and Marques-Ibanez (2009), Köhler (2012)).

(III) Dominance of large financial institutions. Universal global banks were the largest sponsors of off-balance vehicles prior to the crisis (Arteta, Carrey, Correa, and Kotter (2013)).

(IV) Fee-based income. Sponsors of off-balance vehicles earned intermediation and loan servicing fees. Available evidence also shows that sponsors' profits were very small relative to the volume of off-balance intermediation (Acharya, Schnabl, and Suarez (2013), Arteta, Carrey, Correa, and

\footnotetext{
${ }^{1}$ Only $2.5 \%$ of ABCP outstanding as of July 2007 entered default in the period from July 2007 to December 2008 (Acharya, Schnabl, and Suarez (2013)), while at the same time a large share of the structurized products had their ratings downgraded (Coval, Jurek, and Stafford (2009)). Appendix B provides more evidence on the execution of implicit support policies.
} 
Kotter (2013))..$^{2}$

In order to relate the empirical facts, this paper develops a model of bank holding companies (BHCs) granting implicit guarantees. In the model, the BHC consists of two entities: a bank entity investing in risky projects and an off-balance SPV selling projects to investors. The BHC can increase the fee income from its SPV by guaranteeing sold loans with the bank entity's balance sheet.

The main contributions of the paper are threefold. First, it shows that implicit guarantees can arise in equilibrium purely as a result of regulatory arbitrage, also in absence of any information asymmetries between sponsors and investors. In the model it is the foregone intermediation fee income that incentivizes sponsors to keep guarantee promises ex post. Secondly, it allows to study economy-wide consequences of granting implicit guarantees. This is done by endogenizing the size of intermediaries' investments and their risk-taking decisions. Finally, the paper offers important policy implications: as regulatory arbitrage in the form of implicit guarantee contracts can never be ruled out, lowering the capital requirement relative to the level optimal in absence of guarantees is welfare improving when the costs of regulatory interventions are high.

The theoretical set-up can also account for several stylized facts about the shadow banking business prior to the crisis. In the model, for large enough demand for safe $^{3}$ financial assets (empirical fact I), the value of guarantees depends on the bank size. Larger bank investments raise the guarantee repayments expected by SPV investors, who extend their demand for risky projects. This in turn creates incentives for BHCs to increase bank investments even further (empirical fact II). In the presence of the relationship between the bank and the SPV investment decisions, the total amount of credit in the economy is higher than when no guarantees are granted. Bank defaults are more frequent and regulatory costs of providing deposit insurance increase. BHCs with large bank entities can offer higher implicit guarantees than BHCs with small banks, and when bank size heterogeneity is introduced, equilibria with only large BHCs engaging in off-balance activities arise (empirical fact III).

When the SPV market is modeled as a Nash bargaining game between investors and BHCs, BHCs lose control over the SPV project demand. The equilibrium intermediation fee becomes very low and the SPV trading volume increases (empirical fact IV), as investors take into account the impact of their own demand on the fee level.

\footnotetext{
${ }^{2}$ For example, Deutsche Bank reported conduit fees of Euro 6 million relative to total conduit assets of Euro 6.3 billion in year 2007 (Acharya, Schnabl, and Suarez (2013)), and Bank of New York Mellon reported revenues of $\$ 3$ million relative to total assets of $\$ 3.2$ billion in its off-balance vehicles in 2006 (Arteta, Carrey, Correa, and Kotter (2013)), which gives a margin of 10 basis points on vehicles' assets in both cases.

${ }^{3}$ Following Gorton, Lewellen, and Metrick (2012), I call safe financial assets that can be used as money, i.e. in an information-insensitive way.
} 
While guarantees always increase incentives to monitor sold projects, their effect on monitoring of on-balance projects is ambiguous. Interestingly, in the presence of implicit guarantees the incentives to monitor bank projects depend on the profitability of shadow banking activities. Thus, guarantees distort risk-taking incentives and might increase the riskiness of the traditional banking sector.

Finally, regulatory policies play an important role in the expansion of the shadow banking sector in the model. First, when the probability of bank bailouts is high, BHCs are more willing to execute guarantees even if this implies additional default risk. Secondly, high minimum capital requirements contribute to the emergence of the relationship between the bank size and the SPV project demand. This happens as the capital requirement effectively restricts the optimal bank investment in comparison to the size of the shadow banking sector. When the guarantee claims of SPV investors are very high relative to bank proceeds, only partial guarantee repayments are possible. In this case, the amount repaid depends on the total proceeds from the bank entity, and thus on the size of the bank investment.

This paper is structured as follows. Section 2 provides an overview of the existing literature on shadow banking and implicit guarantees. Section 3 presents the problem of a BHC in absence of implicit guarantees, which are introduced in Section 4. Section 5 studies optimal capital requirements in presence of regulatory arbitrage. BHC's monitoring decisions are endogenized in Section 6. A two-period model with fee bargaining is considered in Section 7. Section 8 concludes. All proofs are presented in Appendix C.

\section{Related literature}

This paper contributes to the growing literature on shadow banking and securitization. My model is closest in spirit to the shadow banking models of Gorton and Souleles (2007) and Gennaioli, Shleifer, and Vishny (2013). In Gorton and Souleles (2007) banks grant implicit guarantees to overcome the adverse selection problem arising from the asset sale between the sponsoring bank and the SPV. Executing implicit guarantees can be the equilibrium strategy in a multiperiod game between the sponsor and the SPV clients, but - contrary to my model - it never results in the sponsor's default. In Gennaioli, Shleifer, and Vishny (2013) high loan demand of risk-averse investors motivates securitization, which is a substitute to riskless assets as collateral for riskless debt. However, they abstract from implicit support policies of sponsoring BHCs, and entirely focus on the incentives of BHCs to pool, cut into tranches and sell loans. Neither do they explicitly model the distinction between on-balance and off-balance bank activities.

The incentives of financial intermediaries to engage in off-balance activities have been studied extensively. Empirically, Arteta, Carrey, Correa, and Kotter (2013) find that manager agency 
problems and state support to financial intermediaries were crucial in motivating banks to sponsor off-balance vehicles prior to the global financial crisis. Acharya, Schnabl, and Suarez (2013) find evidence supporting the regulatory arbitrage hypothesis. Their results suggest that most of the credit risk from securitized assets stayed effectively with sponsoring banks, which used off-balance vehicles to reduce their capital requirements.

In the theoretical literature, different aspects of the off-balance activities have been studied separately. Greenbaum and Thakor (1987) and Benveniste and Berger (1987) analyse the safeharbour character of off-balance vehicles. They show that the use of bankruptcy-remote entities can improve the allocation of risk among bank liability holders and alleviate the moral hazard problems created by deposit insurance.

Segura (2013) studies incentives to execute non-contractible implicit guarantees ex post. Execution of guarantees provides a positive signal regarding the sponsor's asset quality to investors deciding on rolling over the existing debt. In Ordoñez (2013) the benefit from executing support is higher when the sponsor faces good investment opportunities. Alternative forms of sponsor' support to off-balance vehicles, such as retaining lowest-grade loan tranches on the sponsor's balance sheet, or credit enhancements in the form of reserve accounts are discussed in Gorton and Souleles (2007) and Pozsar, Adrian, Ashcraft, and Boesky (2010).

Gorton and Pennacchi (1990), and DeMarzo (2005) investigate the securitization process per se. They find that pooling and tranching loans can alleviate information asymmetries and increase efficiency of financial intermediation. Gennaioli, Shleifer, and Vishny (2013) show that this is the case only if agents involving in securitization have rational expectations, i.e. there is no neglected aggregate risk.

The problems related to maturity transformation in off-balance financing have been emphasized by Gorton and Metrick (2010), and Gorton and Metrick (2012). They stress that the short-term character of off-balance conduits makes them particularly sensitive to liquidity problems and the risk of runs. Brunnermeier and Oehmnke (2013) show that borrowers might shorten the maturity of individual creditors' debt contracts because this dilutes other creditors. The borrowers then involve in a "maturity rat race" resulting in an inefficiently short maturity debt structure.

\section{One-period model}

This section considers the problem of bank holding companies in the absence of implicit guarantees. In defining the equilibrium I closely follow Acharya (2003), but I abstract from the regulator's optimization problem. All parameters and variables are summarized in Appendix A. 


\subsection{Model primitives}

Agents in the economy. There are two types of infinitely-lived agents in the economy: a unit mass of risk-neutral bank holding companies and a unit mass of risk-averse investors. Each BHC consists of a bank entity and in addition it can decide to set up an off-balance special purpose vehicle (SPV). BHCs invest in risky projects each period. Investors are characterized by mean-variance preferences and have unlimited access to capital, which they can invest in a safe storage technology, yielding zero net return, or lend to BHCs.

Investment opportunities. Banks are the only legal entities that possess the technology necessary for the investment in risky projects. The return per unit of investment $\tilde{R} \in\{0, R\}$ is realized at the end of the period. Whenever kept on the bank's balance sheet, the risky project yields the positive return with a probability $p: \mathbb{P}(R)=p$, with $p R>1$. If sold to third parties (through the $\mathrm{SPV})$, the project loses quality: the probability of the positive return falls to $\underline{p}$, with $\frac{1}{2}<\underline{p}<p$, and $\underline{p} R>1$. Moreover, a zero return realized on the on-balance project implies a zero return realized on the sold project too, but not the other way round. All project returns and state probabilities are fully observable.

The empirical evidence on asset transfers supports the view that loans sold off-balance have worse quality than loans kept on the bank's balance sheet (Dell'Ariccia, Deniz, and Laeven (2012), Mian and Sufi (2009)). Nevertheless, I assume a lower success probability of the sold projects to obtain a positive value of implicit guarantees in a simplest possible way. The main results extend to the case with the same quality of bank and SPV projects but imperfectly correlated returns.

Monitoring. When BHCs have a possibility to monitor risky projects (Section 6), the monitoring problem is modeled as in Holmstrom and Tirole (1997). After paying the monitoring cost $C$ per unit of investment, the success probability of the on-balance project is $p=p_{H}$, and it is $\underline{p}=\underline{p}_{H}$ (with $\underline{p}_{H}<p_{H}$ ) for the sold project. In the absence of monitoring, the success probabilities are $p_{L}$ for the bank project and $\underline{p}_{L}<p_{L}$ for the sold project. Monitoring decisions are nonverifiable and noncontractible.

Investment costs. As in Acharya (2003), maintaining projects involves costs for the bank, given by the quadratic function $c X^{2}$, with $c>0$ and where $X$ is the size of the bank's investment. In the case of a sale to third parties, the project is removed from the bank's balance sheet and thus there are no maintenance costs of the sold project for the bank. 
Banks. The bank entity finances its intermediation activities with deposits, $D$, and common equity, $K$. Deposits pay a gross rate of return $R_{D}$ and are fully insured by a regulator. The regulator also sets a minimum capital requirement $k$ on bank equity, such that $\frac{K}{X} \geq k$.

BHCs are owned by risk-neutral shareholders who require an expected return on equity of $\delta$, with $\delta>R_{D}$. In this simple way I capture the well-documented preference of financial intermediaries for external funding. As modelling the equity issuance process is not the primary goal of this paper, I also assume that the minimum requirement is always binding.

Special purpose vehicles. Minimum capital requirements and maintenance costs limit the optimal size of bank investment. The BHC can then set up an off-balance SPV to provide intermediation services to investors willing to invest further. For each unit of the intermediated project the SPV charges a fee $s$, which is paid by investors before $\tilde{R}$ is realized, and immediately consumed by BHC shareholders. There are no costs of setting up the SPV, the only role of which is to sell the project originated through the bank entity: it is investors who bear the entire project risk. More precisely, each investor buys a share in one risky project: if the project fails, all investors of the same SPV suffer losses. While the investor may use services of one SPV only, each SPV attracts many clients. As a result, the total SPV investment is treated by the representative investor as given.

Regulatory policies. The regulator guarantees return payments to bank deposits in the case of a bank default. The minimum equity-to-assets ratio $k$ is set by the regulator in an attempt to limit expected costs of deposit insurance. From the regulatory perspective, intermediating projects through the SPV is equivalent to an asset sale (which does not result in additional credit risk for the $\mathrm{BHC}$ ), so the off-balance activity is not subject to the capital requirement. A bank defaults whenever it is not able to repay deposits in full. It is then bailed out by the regulator with probability $q$ and continues operating into the next period. With complementary probability $1-q$ the bank is liquidated and stops operating forever. A BHC stops operating whenever its bank entity shuts down, as the bank is also necessary for intermediation of projects through the SPV.

Implicit guarantees. In Section 4 each BHC can raise the fee income from its SPV by guaranteeing sold projects with the bank entity's proceeds. The guarantee is a promise of the full return $R$ to SPV investors in the case of poor performance of the SPV project and good performance of the bank project. The guarantee is noncontractible, as otherwise the off-balance intermediation would not be recognized as a true asset sale and the SPV would be subject to the capital requirement.

Although the mechanism through which bank proceeds are passed to SPV investors is not 
explicitly modeled, one could think of liquidity guarantees used by banks sponsoring the assetbacked commercial paper conduits prior to the crisis.

\subsection{Benchmark case: no guarantees}

In this section I solve the model assuming an exogenous fee level $s$. In Section 7 the equilibrium fee is an outcome of bargaining between the BHC and investors.

BHC's optimization problem. Similarly to Acharya (2003) all profits generated by BHCs within the period are consumed by shareholders by the start of the next period. As shareholders cannot commit to any dynamic investment strategy, the representative BHC's problem can be expressed as a stationary dynamic program with the following objective:

$$
V_{t}=\max _{X_{B}} \underbrace{\mathbb{E} \Pi\left(X_{B}\right)}_{\text {expected bank profits }}+\underbrace{s X_{S P V}}_{\text {SPV fee income }}+\underbrace{\beta(p+(1-p) q) V_{t+1}}_{\text {discounted continuation value }}
$$

Term $\mathbb{E} \Pi\left(X_{B}\right)$ represents the expected return from the bank entity at the end of the period, and $X_{B}$ stands for the size of the risky project funded by the bank. The fee income from intermediating the risky project via the SPV is equal to $s X_{S P V}$. The bank entity defaults with probability $1-p$, in which case it is bailed out by the regulator with probability $q$. Thus, the BHC's continuation probability is equal to $p+(1-p) q$. The continuation value $V_{t+1}$ is discounted with a factor $\beta \in(0,1)$. Due to the lack of commitment on the side of shareholders, the continuation value is treated by the $\mathrm{BHC}$ as a constant and the $\mathrm{BHC}$ chooses the same values of decision variables each period.

In the absence of implicit guarantees, the representative BHC does not have any impact on the investors' demand for risky projects $X_{S P V}{ }^{4}$, and the bank investment is chosen to maximize the expected profits from the bank entity:

$$
\mathbb{E} \Pi\left(X_{B}\right)=p X_{B}\left(R-(1-k) R_{D}\right)-c X_{B}^{2}-\delta k X_{B}
$$

The objective (2) consists of profits realized in the good state $X_{B}\left(R-(1-k) R_{D}\right)$ multiplied by the probability of a positive return $p$, minus maintenance costs $c X_{B}^{2}$, and minus costs of raising shareholder capital $\delta k X_{B}$. It is maximized for $X_{B}$ equal:

$$
X_{B}^{\mathrm{nr}}=\frac{p\left(R-(1-k) R_{D}\right)-\delta k}{2 c}
$$

where the upper-script "nr" stands for the no recourse case.

\footnotetext{
${ }^{4}$ This is also true when the fee level is endogenized.
} 
Given the optimal bank investment, the BHC's continuation value is an infinite geometric series' sum with the common ratio $\beta(p+(1-p) q)$ :

$$
V_{t+1}=V=\frac{\left[\mathbb{E} \Pi\left(X_{B}\right)+s X_{S P V}\right]}{1-\beta(p+(1-p) q)}
$$

Investors' problem. With mean-variance preferences of investors, the riskless character of bank deposits implies that the demand for them is infinite. At the same time, the supply of deposits is restricted to $(1-k) X_{B}$. Deep-pocket investors can invest further via SPVs. The representative investor's demand for the risky SPV project $X_{I}$ maximizes:

$$
\mathbb{E} U_{X_{I}}=\mathbb{E}\left[\tilde{R}_{S P V}\right] X_{I}-\lambda \operatorname{var}\left[\tilde{R}_{S P V}\right]\left(X_{I}\right)^{2}-(1+s) X_{I}
$$

where $\lambda$ is a measure of investor's risk-aversion, $\mathbb{E}\left[\tilde{R}_{S P V}\right]=\underline{p} R$ and $\operatorname{var}\left[\tilde{R}_{S P V}\right]=\underline{p}(1-\underline{p}) R^{2}$. In the absence of implicit guarantees $X_{I}$ is set to:

$$
X_{I}^{\mathrm{nr}}=\frac{\underline{p} R-1-s}{2 \lambda \underline{p}(1-\underline{p}) R^{2}}
$$

Equilibrium. By symmetry, all BHCs choose the same bank investment level, $X_{B}$, and all investors demand the same amount of SPV projects, $X_{I}$. The equilibrium is defined as an allocation $\left(X_{B}, X_{S P V}, D, X_{I}\right)$ and a price system $\left(s, R_{D}\right)$ where:

1. the representative investor's demand for the SPV project $X_{I}$ maximizes (5) for a given $s$,

2. bank lending $X_{B}$ maximizes the BHC shareholders' objective (2) given $R_{D}$ and subject to the minimum capital requirement $k$,

3. the deposit rate satisfies $R_{D} \geq 1$,

4. there are no short sales: $X_{B}, X_{I} \geq 0$.

Sufficient conditions for the existence of the equilibrium are that it is profitable to take on risk, i.e. $\underline{p} R>1$ and that the maintenance cost function $c X^{2}$ is steep enough, so that bank activities are not extended infinitely. In the equilibrium $X_{B}=X_{B}^{\mathrm{nr}}$ given by $(3), D=(1-k) X_{B}^{\mathrm{nr}}$, and $X_{S P V}=X_{I}=X_{I}^{\mathrm{nr}}$ given by $(6)$. 


\section{Model with implicit guarantees to SPVs}

The only way the BHC can increase the fee income is through the demand for the SPV project: by raising the expected returns or reducing the risk of SPV returns in equation (6). This can be achieved by subsidizing the SPV in the states with poor project performance, using proceeds from the bank entity. Of course, there are many ways in which the BHC could increase the demand for the SPV project: with risk-neutral investors increasing the SPV's rate of return in successful states sufficiently high would have the same effect. However, when investors are risk-averse, the former policy is preferred as it both increases expected returns and decreases the variance of returns.

\subsection{Design of implicit guarantees}

The implicit guarantee is defined as follows:

Definition 1. Through the implicit guarantee, the BHC promises to pay $R$ to the SPV investor when the SPV's project return is zero but the bank's project is successful. The promise is noncontractible. 56

Three important issues follow from the Definition 1. First, the guarantee is necessarily informal, as any formal contract would make the SPV subject to the capital requirement. Because of the non-contractibility, there is always a risk for the investor that the $\mathrm{BHC}$ will not realize the guarantee ex post. As a result, for the guarantee to be granted in equilibrium, an ex post execution condition will need to be satisfied (Section 4.2). Secondly, any implicit guarantee can be realized only if the bank entity has a positive return on its own investment. Thus, the state when the transfer takes place is $(\mathrm{R}, 0)$, realized with probability $p-\underline{p}$. All possible payoff states are listed below.

\begin{tabular}{lll}
\hline Probability & $\begin{array}{l}\text { Return to } \\
\text { the bank }\end{array}$ & $\begin{array}{l}\text { Return to the } \\
\text { SPV }\end{array}$ \\
\hline$\underline{p}$ & $R$ & $R$ \\
$p-\underline{p}$ & $R$ & 0 \\
$1-p$ & 0 & 0 \\
0 & 0 & $R$ \\
\hline
\end{tabular}

\footnotetext{
${ }^{5}$ The way I model implicit guarantees (and shadow banking more in general) is closest to the design of pass-through SPVs in the ABCP market prior to the crisis. The securitization chain was relatively simple in the case of ABCP SPVs, and their main purpose was the regulatory arbitrage. Moreover, in the vast majority of cases the sponsor and the guarantor to SPVs were the same institutions.

${ }^{6}$ More in general, each BHC could chose a repayment fraction $0 \leq \alpha \leq 1$ maximizing the expected profits from the guarantee. Here BHCs can only set $\alpha \in\{0,1\}$ : it simplifies the exposition, while leaving main results unaffected.
} 
Finally, the guarantee repayment is effectively restricted by total proceeds from the bank entity, $R X_{B}$. For both the representative investor and the representative BHC, the implicit guarantee (conditional on being realized) can be written as the minimum of two values:

$$
\begin{gathered}
\text { Guarantee }_{I}=R \times \min \left\{X_{I}, \frac{X_{B}}{X_{S P V}} X_{I}\right\} \\
\text { Guarantee }_{B}=R \times \min \left\{X_{S P V}, X_{B}\right\}
\end{gathered}
$$

Guarantee $_{I}$ represents the amount received back by the investor, Guarantee $_{B}$ stands for the total repayment costs for the BHC. Intuitively, for large enough SPV project demand, the BHC might not be able to realize all guarantees in full. The return payment is then equal to the bank entity's total proceeds, $R X_{B}$, divided among all clients of the SPV, with the single investor receiving back a fraction $\frac{X_{B}}{X_{S P V}}$ of the promised amount. As he is only one of many SPV clients, the representative institutional investor treats $X_{S P V}$ as given.

SPV project demand with implicit guarantees. From the investor's perspective, the guarantee is a put option with a strike price $\frac{R X_{B}}{X_{S P V}}$. Figure 2 plots the guarantee value as a function of the bank investment size $X_{B}$.

[ Figure 2 here ]

In the presence of guarantees, the investor's demand for the risky project is equal to:

$$
X_{I}^{\mathrm{rec}}=\frac{\underline{p} R+(p-\underline{p}) R \min \left\{1, \frac{X_{B}}{X_{S P V}^{\mathrm{rec}}}\right\}-1-s}{2 \lambda \operatorname{var}\left[\tilde{R}_{S P V}^{\mathrm{rec}}\right]} \geq X_{I}^{\mathrm{nr}}
$$

where the upper-script "rec" stands for the recourse case.

Lemma 1. The representative investor's demand for the SPV project is non-decreasing in the size of the bank investment for $\delta<2 p R_{D}$ :

$$
\frac{\partial X_{I}^{r e c}}{\partial X_{B}} \geq 0
$$

Whenever full guarantee repayments are possible, the bank size does not influence the value of guarantees to the investor $\left(\frac{\partial X_{I}^{\text {rec }}}{\partial X_{B}}=0\right)$. Under partial guarantee repayments the repayment expected by each investor increases with the bank size $\left(\frac{\partial X_{I}^{\text {rec }}}{\partial X_{B}}>0\right)$. 
Implicit guarantees and bank investment. For the BHC the benefit of granting guarantees is equal to the increase in the SPV fee income: $s\left(X_{S P V}^{\mathrm{rec}}-X_{S P V}^{\mathrm{nr}}\right)$, minus the expected cost of guarantees' repayments in the state $(R, 0):(p-\underline{p}) R \min \left\{X_{S P V}, X_{B}\right\}$. Figure 3 plots the value of implicit guarantees for the sponsoring BHC for different levels $X_{B}$.

[ Figure 3 here ]

Whenever guarantees are realized and exceed $\left(R-(1-k) R_{D}\right) X_{B}$, the remaining bank proceeds are not sufficient to repay deposits and the bank defaults. Thanks to deposit insurance investors' deposits are unaffected, and the costs of realizing guarantees are effectively passed to the regulator and thus to taxpayers.

Definition 2. Implicit guarantees to SPVs:

1. provide a recourse to bank capital whenever it is the $\mathrm{BHC}$ shareholders only who bear the costs of realizing guarantees: $R X_{S P V} \leq X_{B}\left(R-(1-k) R_{D}\right)$,

2. provide a recourse to deposit insurance whenever the repayment costs are passed to the regulator: $R X_{S P V}>X_{B}\left(R-(1-k) R_{D}\right)$.

As Definition 2 makes clear, the type of recourse provided by guarantees crucially depends on the minimum capital requirement $k$. Intuitively, a high equity-to-assets ratio should increase the bank's capacity to realize guarantee repayments from own capital. However, a high $k$ also restricts the optimal size of the bank activity $\left(\frac{d X_{B}}{d k}<0\right)$. The following Lemma gives the condition under which the second effect prevails:

Lemma 2. Increasing the capital requirement reduces bank's own capacity to realize guarantees without resorting to deposit insurance when the minimum capital requirement is higher than $k^{*}$ :

$$
k^{*}=\frac{\left(R-R_{D}\right)\left(2 p R_{D}-\delta\right)}{2 R_{D}\left(\delta-p R_{D}\right)}
$$

In other words, increasing the minimum capital requirement above $k^{*}$ lowers the total amount of bank capital $k X_{B}$.

Finally, potential guarantee repayments change the representative BHC's objective function. When guarantees provide a recourse to bank capital only, the expected guarantee repayment cost is equal to $(p-\underline{p}) R X_{S P V}^{\mathrm{rec}}$, but the BHC's continuation probability is not affected: 


$$
\begin{aligned}
& \max _{X_{B}} \underbrace{s X_{S P V}^{\mathrm{rec}}}_{\text {SPV fee income }}+\underbrace{p\left(R-(1-k) R_{D}\right) X_{B}}_{\text {bank profits when SPV successful }}+(p-\underline{p}) \underbrace{\left[\left(R-(1-k) R_{D}\right) X_{B}-R X_{S P V}^{\mathrm{rec}}\right]}_{\text {bank profits when guarantees repaid }} \\
& -c\left(X_{B}\right)^{2}-\delta k X_{B}+\underbrace{\beta(p+(1-p) q) V^{\text {rec }}}_{\text {discounted continuation value }}
\end{aligned}
$$

When guarantees provide a recourse to deposit insurance, all bank proceeds $R X_{B}$ are paid out to SPV investors, and the bank entity defaults on its deposits. The new continuation probability is equal to $\underline{p}+(1-\underline{p}) q$ : it depends only on the bailout probability and on the success probability of the SPV project. The BHC's objective is:

$$
\max _{X_{B}} \underbrace{s X_{S P V}^{\mathrm{rec}}}_{\text {SPV fee income }}+\underbrace{p\left(R-(1-k) R_{D}\right) X_{B}}_{\text {bank profits when SPV successful }}-c\left(X_{B}\right)^{2}-\delta k X_{B}+\underbrace{\beta(\underline{p}+(1-\underline{p}) q) V^{\mathrm{rec}}}_{\text {discounted continuation value }}
$$

Equilibrium with implicit guarantees. Proposition 1 summarizes bank and SPV investment choices when implicit guarantees are granted.

Proposition 1. (Bank and SPV investments with implicit guarantees.) With implicit guarantees granted in equilibrium, and when $k>k^{*}$ :

1. For a low minimum capital requirement: $k \in\left(k^{*}, \bar{k}_{1}\right]$, the guarantees provide a recourse to bank capital. The bank investment is equal to the no-recourse level $X_{B}^{n r}$ and the representative investor's demand for the SPV project is:

$$
X_{I}^{r e c}=\frac{p R-1-s}{2 \lambda p(1-p) R^{2}}>X_{I}^{n r}
$$

2. For a high minimum capital requirement: $k \geq \bar{k}_{1}$, the guarantees provide a recourse to deposit insurance with:

- full guarantee repayments, for $k \in\left(\bar{k}_{1}, \bar{k}_{2}\right]$, as long as $\bar{k}_{2}>\bar{k}_{1}$. The SPV investment is the same as in (11), but the bank investment falls to:

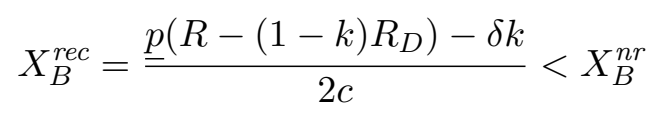

- partial guarantee repayments for $k>\bar{k}_{2}>\bar{k}_{1}$ OR if $k>\bar{k}_{1}>\bar{k}_{2}$. The representative 
investor's SPV project demand is increasing in the bank investment size:

$$
X_{I}^{r e c}=\frac{\underline{p} R+(p-\underline{p}) \frac{R X_{B}^{r e c}}{X_{S P V}^{r e c}}-1-s}{2 \lambda \operatorname{var}\left[\tilde{R}_{S P V}^{r e c}\right]}>X_{I}^{n r}
$$

and the representative $B H C$ 's bank investment $X_{B}^{\text {rec }}$ solves:

$$
\max _{X_{B}}\left[s X_{S P V}^{r e c}\left(X_{B}\right)+\underline{p}\left(R-(1-k) R_{D}\right) X_{B}-c\left(X_{B}\right)^{2}-\delta k X_{B}+\beta(\underline{p}+(1-\underline{p}) q) V^{r e c}\right]
$$

3. In equilibrium $X_{I}^{r e c}=X_{S P V}^{r e c}$.

SPV project demand is always higher under BHC guarantees than in absence of the implicit recourse. It is independent of the bank investment decision as long as implicit guarantees are fully repaid (eq. (11)). Once only partial repayments are feasible, a higher bank investment raises the guarantee repayment each SPV investor can expect, and the demand for the SPV project increases in the size of the BHC's bank entity $\left(\frac{\partial X_{I}^{\text {rec }}}{\partial X_{B}}>0\right.$ in Lemma 1$)$.

The bank entity size is equal to the "no recourse" level as long as executing guarantees does not result in the bank's default and if full guarantee repayments are feasible (recourse to bank capital only). Once the guarantees provide a recourse to deposit insurance, the optimal bank size changes.

First, the BHC would like to reduce the investment to account for lost bank profits from guarantee repayments $\left(X_{B}^{\mathrm{rec}}<X_{B}^{\mathrm{nr}}\right.$ in equation (12)). On the other hand, when only partial guarantee repayments are feasible, a higher bank investment increases the demand for SPV projects $\left(X_{S P V}^{\mathrm{rec}}\left(X_{B}\right)\right.$ in eq. (14)). In this case the BHC has incentives to increase bank investment in order to boost SPV fee income even further. Lemma 3 presents the condition under which the latter effect prevails and the total volume of credit in the economy exceeds the "no recourse" level.

Lemma 3. When guarantees provide a recourse to deposit insurance and only partial guarantee repayments are feasible, multiple equilibria arise. As long as $\lambda<\hat{\lambda}$, the size of the bank investment always exceeds the "no recourse" investment level $X_{B}^{n r}$, and the total project investment $X_{B}^{r e c}+X_{S P V}^{r e c}$ is higher than in absence of implicit guarantees.

A low value of $\lambda$ corresponds to a high demand for SPV projects in absence of guarantees and a strong response to an implicit guarantee offer $\left(\frac{d^{2} X_{I}}{d p d \lambda}<0\right)$. Intuitively, for the guarantees to have a large effect on the SPV project demand, investors cannot be too risk-averse: for highly risk-averse investors the remaining riskiness of the SPV project is more important than the reduction of the default probability via implicit guarantees. 
In the opposite case - for relatively low values of $\lambda$ - the drop in the default probability has a big impact on investors' demand. This incentivizes BHCs to high increases in their own bank investments. For $\lambda<\hat{\lambda}$ both the SPV project investment and the bank investment increase beyond the "no recourse" levels. As guarantees provide a recourse to deposit insurance in this case, this implies more frequent bank defaults and higher costs of providing deposit insurance for the regulator.

Capital requirements and implicit guarantees. The results from Proposition 1 can be summarized graphically in terms of the minimum capital requirement $k$ and the risk-aversion parameter $\lambda$ :

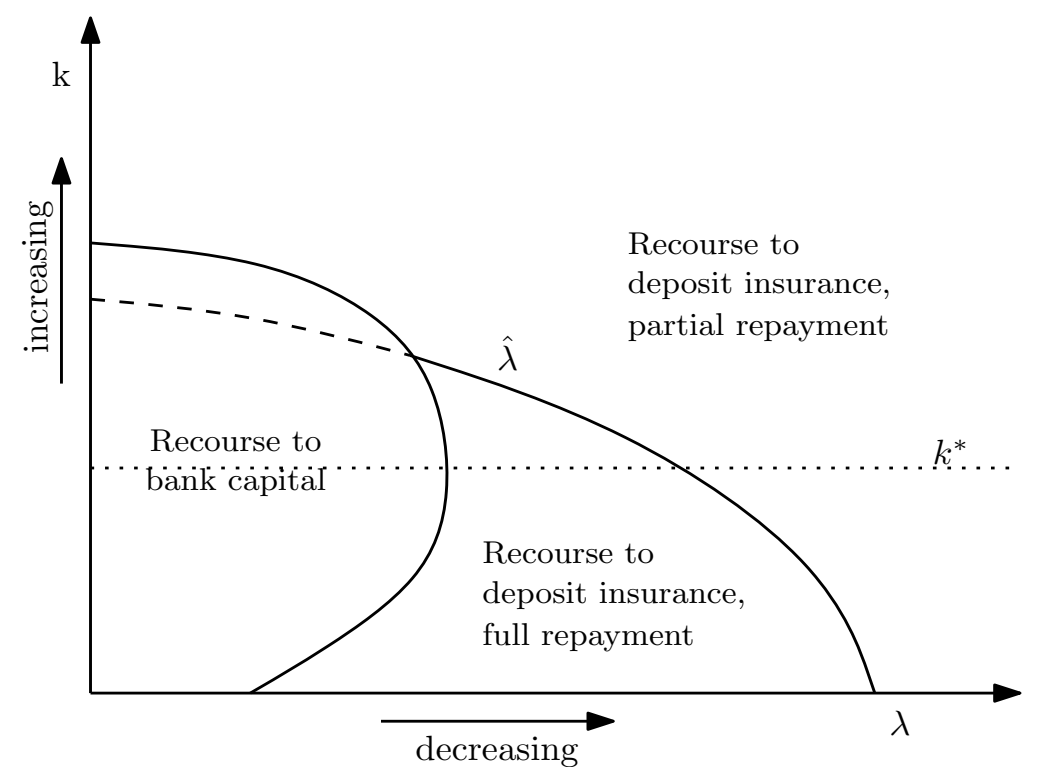

Figure 1: Types of recourse as a function of $k$ and $\lambda$.

As long as $k>k^{*}$, increasing the minimum requirement reduces the available amount of bank capital (keeping $\lambda$ fixed). This makes the execution of implicit guarantees without a recourse to deposit insurance less likely and partial guarantee repayments - more likely $\left(\frac{d \hat{\lambda}}{d k}>0\right)$. By Lemma 3 , for $\lambda<\hat{\lambda}$ the bank investment is higher than in absence of implicit guarantees. Thus, costs of providing deposit insurance increase also in the states when guarantees cannot be claimed (both bank and SPV projects fail). This result shows that setting capital requirements at a very high level might be inefficient in achieving regulatory goals of restricting bank lending and controlling costs of deposit insurance as long as regulatory arbitrage possibilities exist.

The question of optimal capital requirements in presence of implicit guarantees is investigated in Section 5. 


\subsection{Execution of guarantees ex post}

As guarantees are noncontractible, the representative BHC might refuse to realize guarantees ex post. However, if the BHC fails to repay investors, they might not respond to a similar guarantee offer in the future. As a result, for the guarantees to be granted in equilibrium, an ex post execution condition will need to hold.

To avoid analyzing alternative punishment strategies in a multiperiod game, I simply assume that if the BHC refuses to repay the guarantees, the demand for the SPV project will fall to the "no recourse" level in all future periods. In other words, the investors will never respond to a guarantee promise again.

Proposition 2. (Guarantee execution condition.) For guarantees to SPV investments to be granted in equilibrium the ex post execution condition needs to hold:

1. for the recourse to bank capital: $R X_{I}^{r e c} \leq \beta\left(V^{r e c}-V^{n r}\right)$,

2. for the recourse to deposit insurance: $X_{B}^{r e c}\left(R-(1-k) R_{D}\right) \leq \beta\left(q V^{r e c}-V^{n r}\right)$.

Whenever the ex post execution condition is not satisfied, no guarantees are granted in equilibrium: the bank investment is equal to $X_{B}^{n r}$, and the $S P V$ project demand is given by $X_{I}^{n r}$.

The guarantee execution condition takes different forms for the recourse to deposit insurance and for the recourse to bank capital. Under the recourse to bank capital executing guarantees does not change the default probability of the BHC. Therefore, for the guarantees to be granted and realized in equilibrium, the repayment costs have to be lower than the present value of the fall in the SPV fee income following a refusal to pay out investors.

In the case of the recourse to deposit insurance execution of guarantees always leads to the bank entity's default. After a bank default, the BHC continues operating only if bailed out by the regulator (with a probability $q$ ). Therefore, the recourse to deposit insurance is an equilibrium strategy if the continuation value corrected for the decreased probability of survival $\left(\beta q V^{\mathrm{rec}}\right)$ is higher than the sum of savings from not realizing guarantees and the continuation value under no recourse policy $\left(X_{B}^{\mathrm{rec}}\left(R-(1-k) R_{D}\right)+\beta V^{\mathrm{nr}}\right)$.

The ex post execution condition is more likely to be satisfied for high bank bailout probabilities. Importantly, when $q=0$ and the bank is always liquidated after a default, the guarantees with a recourse to deposit insurance are never executed, and thus are never granted in equilibrium. This is, however, a feature particular for the assumed simple model specification. In Section 7 implicit guarantees can provide a recourse to deposit insurance also in the absence of bank bailouts. Nevertheless, regulatory interventions always increase the value of guarantees to the sponsoring institutions. 
Corollary 1. A high enough probability of bank bailouts can make the recourse to deposit insurance an equilibrium policy also in the case when it is never granted in the absence of bank bailouts. Raising $q$ always relaxes the guarantee execution condition.

\subsection{Heterogenous BHCs}

Before the recent financial crisis, primarily large global intermediaries involved in shadow activities (empirical fact III). One explanation for this tendency can be the difference in the value of implicit guarantees between large and small sponsors of SPVs.

Suppose that a fraction $\phi$ of banks in the traditional banking sector are now "efficient", and the complimentary fraction are "inefficient". The two types of banks differ in the maintenance cost technology. For a given investment size, efficient banks' maintenance costs are always lower than for inefficient banks: $c_{L}<\phi c_{S}$ in $c_{i} X^{2}$, where $i=\{L, S\}$.

Bank heterogeneity with no implicit guarantees. In the absence of guarantees the SPV project demand is independent of the bank lending size: all SPVs intermediate the same amount of risky projects, given by $X_{I}^{\mathrm{nr}}$ in (6). The bank sizes are equal to:

$$
\begin{gathered}
X_{B, L}^{\mathrm{nr}}=\frac{p\left(R-(1-k) R_{D}\right)-\delta k}{2 c_{L}} \\
X_{B, S}^{\mathrm{nr}}=\frac{p\left(R-(1-k) R_{D}\right)-\delta k}{2 c_{S}}<X_{B, L}^{\mathrm{nr}}
\end{gathered}
$$

for the efficient and for the inefficient BHCs respectively. I further call banks (BHCs) with the maintenance cost parameter $c_{L}$ "large" banks (BHCs), and banks (BHCs) with the cost parameter $c_{S}$ - "small".

Bank heterogeneity with implicit guarantees. Under implicit guarantees and for high demand for SPV projects the BHCs with small bank entities are not able to promise the same value of guarantees as large BHCs. The off-balance market becomes separated, with large BHCs dominating the shadow banking sector fully or partially. Proposition 3 summarizes the model outcomes in the presence of implicit guarantees.

Proposition 3. Bank heterogeneity and separation in the shadow banking. With the ex post execution condition satisfied, when there are differences in the bank entities size:

1. (No separation) For a low minimum capital requirement $k \leq \tilde{k}_{1}$ both types of BHCs offer full guarantee repayments. All SPVs are of the same size, while there is a mass $\phi$ of large 
banks and a mass $1-\phi$ of small banks in the traditional banking sector. Large banks invest (15) and small banks invest (16).

2. (Full market separation) For the minimum capital requirement $k \in\left(\tilde{k}_{1}, \tilde{k}_{2}\right]$ only BHCs with large bank entities offer full guarantee repayments and stay in the SPV market. Bank investments are equal to (15) for large banks and (16) for small banks.

3. (Partial market separation) When $k>\tilde{k}_{2}$, only partial guarantee repayments are feasible for both types of BHCs. In equilibrium BHCs with large banks attract a share $\nu>\phi$ of investors in the SPV market, and BHCs with small bank entities have a $1-\nu$ share of the SPV market. The share $\nu$ is such that:

$$
\frac{1-\nu}{1-\phi} X_{B, L}^{r e c}=\frac{\nu}{\phi} X_{B, S}^{r e c}
$$

where the bank investments $X_{B, L}^{r e c}, X_{B, S}^{r e c}$, and the $S P V$ project demand are given by conditions corresponding to equations (13) and (14) in Proposition 1.

As large banks are expected to generate higher end-of-period proceeds than small banks, this directly translates to a higher value of guarantees promised to SPV investors. Depending on the relative size of the SPV project demand against the size of bank entities, different scenarios in the SPV market are possible.

When full guarantee repayments are feasible, both types of BHCs are present in the SPV market. The full separation in the SPV market takes place when only large BHCs are able to promise full guarantee repayments. However, full repayments are not sustainable if the increased demand for SPV services exceeds guarantee capacities of large BHCs too (as all clients of small BHCs now switch to large BHCs). In this case both types of BHCs are present in the SPV market and offer partial guarantees, but large BHCs attract a higher share of investors $\left(\frac{\nu}{\phi}\right)$ than small BHCs do (partial separation).

\section{Implicit guarantees and optimal capital requirements}

In this Section I investigate the question of optimal capital requirements from the perspective of a welfare-maximizing regulator. The results from Section 4 indicate that there might be a difference between the minimum capital requirement optimal in the presence of implicit guarantees to shadow banking and the level optimal in the absence of implicit recourse contracts. 


\subsection{Demand for financial assets}

The welfare analysis is conducted assuming constant demand for financial assets $W$. The constant demand can be thought of as analogous to the "safe" financial debt of Gorton, Lewellen, and Metrick (2012). They find that while the total amount of financial assets in the US has increased exponentially, the share of assets perceived as safe in the total assets has been remarkably stable (at around $33 \%$ ) over the last 60 years. They define as "safe" financial assets that are insensitive to information on the issuer (thus, immune to adverse-selection problems), and relate their finding to the stable need for financial assets that can be used as money, i.e. in an information-insensitive manner.

In the model, demand for safe assets is covered by bank deposits $D$, off-balance investments $X_{\mathrm{SPV}}$, and safe storage (e.g. cash) $C=W-D-X_{\mathrm{SPV}}$. While the SPV-investor contract is not a debt contract per se, both bank deposits as well as SPV projects from the model in Section 4 are "safe" in the sense of Gorton, Lewellen, and Metrick (2012): their returns are perfectly observable and realized with exogenous probabilities. ${ }^{7}$ For simplicity I consider the most interesting case where $W$ is sufficiently large for the guarantees to have an effect on the SPV project demand: $W>X_{B}^{\mathrm{nr}}+X_{\mathrm{SPV}}^{\text {full }}$.

\subsection{Regulatory objective}

The regulator chooses the minimum capital requirement to maximize a utilitarian welfare function, while for simplicity it is assumed that he always bails out a defaulting bank: $q=1$. This is possible when the regulator cannot credibly commit not to bail out a bank in the presence of high bank bankruptcy costs. ${ }^{8}$ The only costs of regulatory bailouts come from providing deposit insurance. Similarly to Acharya and Yorulmazer (2008) the regulatory interventions are costly: providing one unit of funds to depositors requires collecting $F>1$ of funds via distortive taxes. In the absence of implicit guarantees the welfare function of the regulator is:

$$
\begin{gathered}
\text { Welfere }^{\mathrm{nr}}=\underbrace{\mathbb{E} \Pi_{B}}_{\text {bank sector profits }}+\underbrace{\mathbb{E} U_{I}}_{\text {investors' utility }}-(1-p) \underbrace{F R_{D}(1-k) X_{B}^{\mathrm{nr}}}_{\text {cost of deposit insurance }}= \\
p R X_{B}^{\mathrm{nr}}-\delta k X_{B}^{\mathrm{nr}}-c\left(X_{B}^{\mathrm{nr}}\right)^{2}+\underline{p} R X_{\mathrm{SPV}}^{\mathrm{nr}}-\lambda \underline{p}(1-\underline{p}) R^{2}\left(X_{\mathrm{SPV}}^{\mathrm{nr}}\right)^{2} \\
-X_{\mathrm{SPV}}^{\mathrm{nr}}-(1-k) X_{B}^{\mathrm{nr}}-(F-1)(1-p) R_{D}(1-k) X_{B}^{\mathrm{nr}}
\end{gathered}
$$

\footnotetext{
7 The success probabilities for both types of projects should be sufficiently high as well.

${ }^{8}$ Dewatripont and Freixas (2011) argue that bank bankruptcies have higher social costs - in terms of real economic activity - than bankruptcies of other firms and that therefore it is important to keep bank operations going during the entire resolution process.
} 
where $(1-k) X_{B}^{\mathrm{nr}}=D$.

\subsection{Optimal capital requirements under regulatory arbitrage}

Implicit guarantees to the shadow banking sector affect total welfare in two ways. On the positive side, guarantees allow for a transfer of risk from risk-averse investors to risk-neutral BHCs, thus increasing welfare. On the negative side, guarantees incentivize over-investment in the less productive off-balance projects, affect the bank investment choices, and (under the recourse to deposit insurance) increase social costs of providing deposit insurance. Proposition 4 summarizes the net welfare effects of different recourse types.

Proposition 4. (Welfare effects of implicit guarantees with unchanged capital requirements.) Implicit guarantees with a recourse to bank capital are always welfare-improving. The net welfare effect of guarantees with a recourse to deposit insurance depends on the minimum capital requirement $k$ in a non-linear way.

Under the recourse to bank capital there are no additional fiscal costs of deposit insurance, and risk-shifting between investors and BHCs improves welfare. On the contrary, granting a recourse to deposit insurance always involves additional costs of providing deposit insurance. Depending on the actual level of the minimum capital requirement, the net welfare effect can be either positive or negative.

Changing capital requirements. The above welfare comparisons hold true as long as the capital requirement does not change after implicit guarantees are granted. From Lemma 3, as long as $\lambda<\hat{\lambda}$ guarantees always provide a recourse to deposit insurance with partial repayments. However, for high and medium values of $\lambda$, the regulator can affect the type of the recourse provided by implicit guarantees. In particular, when $k>k^{*}$, reducing the minimum requirement can move the economy from the recourse to deposit insurance to the recourse to bank capital, and from partial guarantee repayments to full guarantee repayments.

A more interesting question is thus whether the regulator can increase the welfare by changing $k$. This issue should be of particular relevance for policy makers, as implicit guarantee contracts by definition - can never be eliminated entirely. The next proposition summarizes the main results of the welfare analysis when capital requirements can be adjusted.

Proposition 5. (Welfare effects of changing capital requirements.) When $k>k^{*}, a$ reduction of the minimum capital requirement $k$ to a $k^{\text {new }}$ such that:

1. there is a shift from the recourse to deposit insurance with partial guarantee repayments to the recourse to bank capital is always welfare improving for $F>\tilde{F}_{1}\left(k, k^{n e w}\right)$ when $\lambda<\hat{\lambda}$. 
2. there is a shift from the recourse with partial repayments to the recourse with full guarantee repayments is always welfare improving for $F>\tilde{F}_{2}\left(k, k^{n e w}\right)$ when $\lambda<\hat{\lambda}$.

3. there is a shift from the recourse to deposit insurance with full repayments to the recourse to bank capital is always welfare improving if $\lambda<\underline{\lambda}$. When $\lambda>\underline{\lambda}$, the reduction is still welfare-improving for $F<\tilde{F}_{3}\left(k, k^{\text {new }}\right)$.

The condition $\lambda<\hat{\lambda}$ guarantees that both bank and SPV investments are higher under the recourse with partial guarantee repayments than in absence of guarantees. In this case, whenever the cost of providing deposit insurance is sufficiently high, a shift from a recourse with partial repayments is welfare improving. This reduces the amount of lending in the economy and prevents the reinforcing relationship between the bank and SPV investment decisions.

The welfare comparison between the recourse to bank capital and the recourse to deposit insurance with full repayments is more complicated. First, as the size of bank investment is lower in the latter case, it might happen that the costs of providing deposit insurance are actually lower under the recourse to deposit insurance. This is when $\lambda>\underline{\lambda}$ : the demand for SPV projects does not respond sufficiently high to guarantee offers, and thus costs of more frequent bank defaults under the recourse to deposit insurance are out-weighted by the cost reduction due to lower bank size. In the opposite case, $\lambda>\underline{\lambda}$, fiscal costs are actually higher under the recourse to deposit insurance than under recourse to bank capital and a shift to the recourse to bank capital is always welfare-improving.

Discussion. The above analysis incorporates only some effects of capital requirements. For example, the bank portfolio choice is treated as given in the model, while is plausible that high capital requirements restrict ex ante risk-taking incentives, thus making the financial system more stable. At the same time the capital requirements are assumed to be always binding and fixed along the business cycle, which eliminates potential positive effects of counter-cyclical capital requirements on reducing fluctuations of credit along the cycle. Nevertheless, the key qualitative results of the analysis still hold in a more general setting, as long as the potential for regulatory arbitrage is not eliminated.

\section{$6 \quad$ Loan monitoring with implicit guarantees}

While the implicit guarantees have received a considerable attention in both theoretical and empirical literature, their impact on the sponsor's risk-taking incentives has not yet been analyzed 
in a structured way. In this Section I consider the issue by allowing the BHCs to exert costly monitoring of both the on-balance and the off-balance projects.

\subsection{Monitoring decisions in absence of guarantees}

To consider the impact of implicit guarantees on the BHC's risk-taking in a compact manner, suppose for purposes of this Section that the amount of available bank capital is now restricted to $\underline{K}$, which limits the bank investment to some $\underline{X}_{B} \leq \frac{p_{L}\left(R\left(1-k R_{D}\right)-\delta k\right.}{2 c}$. The bank size is now independent of the monitoring problem. The BHC has to make two decisions: whether to monitor the bank project and whether to monitor the project sold through the SPV. Lemma 4 summarizes the BHC's monitoring choices.

Lemma 4. In the absence of implicit guarantees, and when the bank investment is limited to $\underline{X}_{B}$, the representative $B H C$ :

1. never monitors the project sold to investors through the SPV,

2. monitors the bank project if and only if $C \leq \bar{C}$, where:

$$
\bar{C}=\left(p_{H}-p_{L}\right)[\underbrace{\left(R-(1-k) R_{D}\right)}_{\text {current period loss }}+\underbrace{(1-q) \frac{\beta V^{n r}}{\underline{X}_{B}}}_{\text {continuation value loss }}]
$$

As the monitoring effort is neither observable nor contractible, the $\mathrm{BHC}$ has no incentives to monitor the sold project. Investors internalize the inability of the BHC to commit to monitoring and adjust their SPV investment level accordingly. The bank project is monitored only if the monitoring cost is sufficiently low.

\subsection{Implicit guarantees and monitoring}

The BHC decides now whether to monitor or not the investment projects after granting implicit guarantees to SPV investors. Denote by $X_{S P V}^{\mathrm{m}}$ the SPV project demand when the monitoring is undertaken and by $X_{S P V}^{\mathrm{nm}}$ if it is not (with $X_{S P V}^{\mathrm{m}} \geq X_{S P V}^{\mathrm{nm}}$ ). Lemma 5 summarizes monitoring decisions of the BHC in the presence of implicit guarantees.

Lemma 5. In the presence of implicit guarantees, and when the bank size is restricted to $\underline{X}_{B}$, the representative $\mathrm{BHC}$ : 
1. monitors the $S P V$ project for the monitoring cost low enough: for $C \leq \tilde{C}_{1}$ under the recourse to bank capital, and for $C \leq \tilde{C}_{2}$ under the recourse to deposit insurance, with:

$$
\begin{gathered}
\tilde{C}_{1}=R\left(\underline{p}_{H}-\underline{p}_{L}\right) \\
\tilde{C}_{2}=\frac{s\left(X_{S P V}^{m}-X_{S P V}^{n m}\right)+\left(\underline{p}_{H}-\underline{p}_{L}\right)\left[\left(R-(1-k) R_{D}\right) \underline{X}_{B}+\beta(1-q) V^{r e c}\right]}{X_{S P V}^{m}}
\end{gathered}
$$

2. monitors the bank project for the monitoring cost below the thresholds: $\underline{C}_{1}$ under the recourse to bank capital, and $\underline{C}_{2}$ under the recourse to deposit insurance, where:

$$
\begin{gathered}
\underline{C}_{1}=\bar{C}+\frac{\left(s+\left(\underline{p}-p_{H}\right) R\right)\left(X_{S P V}^{m, b}-X_{S P V}^{n m, b}\right)-\left(p_{H}-p_{L}\right) R X_{S P V}^{n m, b}}{\underline{X}_{B}} \\
\underline{C}_{2}=\frac{s\left(X_{S P V}^{m, b}-X_{S P V}^{n m, b}\right)}{\underline{X}_{B}}
\end{gathered}
$$

Monitoring of the SPV project increases incentives to monitor the bank project under the recourse to bank capital: $\frac{d \underline{C}_{1}}{d \underline{p}}>0$. Under the recourse to deposit insurance, when full repayments are possible there is no effect of SPV monitoring on bank monitoring, and the effect is ambiguous when only partial repayments are feasible: $\frac{d \underline{C}_{2}}{d \underline{p}} \lessgtr 0$.

$X_{S P V}^{\mathrm{nm}, \mathrm{b}}$ in Lemma 5 is the SPV project investment when the bank project is not monitored, and $X_{S P V}^{\mathrm{m}, \mathrm{b}}$ - when the bank project is monitored.

Introduction of implicit guarantees always increase incentives of the BHC to monitor the SPV project: the monitoring threshold is now positive $\left(\tilde{C}_{1}>0, \tilde{C}_{2}>0\right)$. This happens as implicit guarantees create a direct link between the BHC's profits and the success probability of the SPV project. First, monitoring of the SPV project reduces the probability of guarantee repayments. Secondly, when guarantees provide the recourse to deposit insurance, the BHC does not default only when both the bank and the SPV projects are successful. This gives additional incentives to monitor the SPV project.

Introduction of guarantees does not necessarily increase the monitoring of the bank project in comparison to the "no recourse" case. On one hand, monitoring of the bank project increases the SPV project demand (from $X_{S P V}^{\mathrm{nm}, \mathrm{b}}$ to $X_{S P V}^{\mathrm{m}, \mathrm{b}}$ ). On the other hand, bank proceeds are sometimes used to repay guarantees, which decreases the expected profit from the bank project. Moreover, when guarantees provide the recourse to deposit insurance, the BHC's continuation probability depends only on the success probability of the sold project. This additionally reduces the returns from monitoring of the bank project. 
Interestingly, the overall impact of implicit guarantees on incentives to monitor the bank project depends on the relative profitability of the shadow banking business: both monitoring cost thresholds $\underline{\mathrm{C}}_{1}$ and $\underline{\mathrm{C}}_{2}$ depend on the fee level $s$, and the response of the SPV project demand to implicit guarantees $\left(X_{S P V}^{\mathrm{nm}, \mathrm{b}}-X_{S P V}^{\mathrm{m}, \mathrm{b}}\right)$. The introduction of guarantees creates perverse monitoring incentives in the traditional banking sector, where the decision to monitor the bank project depends on the profitability of the off-balance project.

Finally, monitoring decisions are now interdependent. Under the recourse to bank capital incentives to monitor the bank project are higher when the SPV project is monitored, because a higher SPV project success probability reduces the likelihood of guarantee repayments, increasing profitability of the bank project (complementarity effect). This effect is also present under the recourse to deposit insurance. However, under the recourse to deposit insurance there is also a subtitutability effect from SPV monitoring, as the BHC's continuation probability only depends on the success probability of the SPV project.

Figure 4 presents bank project monitoring thresholds $\bar{C}, \underline{\mathrm{C}}_{1}$, and $\underline{\mathrm{C}}_{2}$ as functions of the SPV project success probability.

[ Figure 4 here ]

\section{Two-stage model with endoguenous fee}

In this Section the intermediation fee level $s$ is set through a bargaining process between BHCs and investors. This creates additional incentives for BHCs to grant implicit guarantees, as they increase both the SPV project demand and the equilibrium fee level. Secondly, as long as investors have positive bargaining power, they demand the amount of the SPV project that minimizes the fee they have to pay. This mechanism is a possible explanation to the empirically observed low net profits accompanied by high trading volumes in the off-balance vehicles prior to the recent financial crisis (empirical fact IV).

As a robustness check, I next extend the benchmark model to include a two-stage return structure. In this setting, the recourse to deposit insurance can be granted in equilibrium also in the absence of bank bailouts, i.e. when $q=0$.

\subsection{Model with fee bargaining}

The SPV fee $s$ is set through a price bargaining process between the SPV and each investor at the beginning of the representative period. BHCs possess bargaining power $\gamma \in[0,1]$, as they are 
the only agents with the project intermediation technology, while each investor is given a $1-\gamma$ bargaining power. Investors are sophisticated players realizing that they are the only potential clients of SPV services. Consider the representative SPV-investor pair that involves in a bargaining process. The equilibrium fee level $s^{*}$ is then a solution to the Nash bargaining problem with weights $\gamma$ and $1-\gamma$ :

$$
s^{*}=\arg \max _{s>0}\left(s X_{I}\right)^{\gamma}\left(\mathbb{E} U_{X_{I}}\right)^{1-\gamma}
$$

Terms in parentheses in (24) represent the benefits of the SPV (BHC) and of the investor from a successful match. The outside options for the two counterparties are zero. In the absence of implicit guarantees the fee level solving (24) is:

$$
s^{*}=\gamma\left[\mathbb{E}\left[\tilde{R}_{S P V}\right]-1-\lambda \operatorname{var}\left[\tilde{R}_{S P V}\right]\right]
$$

where $\mathbb{E}\left[\tilde{R}_{S P V}\right]=\underline{p} R$ and $\operatorname{var}\left[\tilde{R}_{S P V}\right]=\underline{p}(1-\underline{p}) R^{2}$. The investor's demand for the SPV project is implicitly given by the first-order condition:

$$
\mathbb{E}\left[\tilde{R}_{S P V}\right]-\left(1+s^{*}\right)-\frac{\partial s^{*}}{\partial X_{I}} X_{I}=2 \lambda \operatorname{var}\left[\tilde{R}_{S P V}\right] X_{I}
$$

The investor incorporates impact of his own demand $X_{I}$ on the intermediation fee (term $\frac{\partial s^{*}}{\partial X_{I}}$ in (26)). Using equations (25) and (26), the representative investor's demand for the SPV project is:

$$
X_{I}^{\mathrm{nr}}=\frac{\underline{p} R-1}{2 \lambda \underline{p}(1-\underline{p}) R^{2}}
$$

and it is independent of the fee level, which itself is equal to:

$$
s^{\mathrm{nr}}=\frac{\gamma(\underline{p} R-1)}{2}
$$

In the presence of implicit guarantees the expected return from the SPV project increases, and the fee level increases too:

$$
s^{\mathrm{rec}}=\frac{\gamma\left(\underline{p} R+(p-\underline{p}) R \min \left\{1, \frac{X_{P}^{\mathrm{rec}}}{X_{S P V}^{\text {eec }}}\right\}-1\right)}{2} \geq s^{\mathrm{nr}}
$$

The representative investor's demand for the SPV project when implicit guarantees are granted is equal to:

$$
X_{I}^{\mathrm{rec}}=\frac{\underline{p} R+(p-\underline{p}) R \min \left\{1, \frac{X_{B}^{\mathrm{rec}}}{X_{S P V}^{r e c}}\right\}-1}{2 \lambda \operatorname{var}\left[\tilde{R}_{S P V}^{\mathrm{rec}}\right]}
$$


It is straightforward to show that all the results from Section 3 hold also when the fee level is endogenous, so I skip the exposition of equilibrium allocations. Lemma 6 establishes the most interesting result when bargaining over the fee level is introduced.

Lemma 6. When investors have positive bargaining power, the demand for SPV projects does not depend on the fee level charged by the SPV. Each SPV takes as given the intermediation fee level, which itself is increasing in the bargaining power of the $S P V, \gamma$.

The result in Lemma 6 follows from the fact that each investor realizes that the more of loans he demands, the lower will be the fee charged by the SPV. He chooses $X_{I}$ that minimizes the fee level (empirical fact IV), given his bargaining power, $\gamma$. Moreover, as long as investors have a positive bargaining power, the representative $\mathrm{BHC}$ does not have any impact on the demand for its own loans through the fee level.

\subsection{Model with a middle-date return and fee bargaining}

The model from Section 3 is now extended to include a two-stage payoff structure. In this version of the model, the regulator never bails out a defaulting bank.

Investment opportunities. Returns from the risky projects are now realized in two stages: at the middle date and at the end of the period. At the middle date a unit size project on the bank's balance sheet pays:

$$
\tilde{R}_{1}= \begin{cases}r & \text { with } \mathbb{P}(r)=p \\ 0 & \text { with } \mathbb{P}(0)=1-p\end{cases}
$$

For the projects sold to investors through the SPV, the probability of the positive middle-date return is again $\underline{p}$, with $\underline{p}<p$ and the correlation structure defined as in Section 3 . At the end of the period, independently of the middle date return, both the bank project and the SPV project pay:

$$
\tilde{R}_{2}= \begin{cases}R_{H} & \text { with } \mathbb{P}\left(R_{H}\right)=m \\ R_{L} & \text { with } \mathbb{P}\left(R_{L}\right)=1-m\end{cases}
$$

Thus, in comparison to the on-balance project, the sold project has a lower probability of a positive middle-date return only.

Assumption 1: The returns to the bank project are characterized by the following conditions:

1. $r+R_{H}>(1-k) R_{D}$ and $r+R_{L}>(1-k) R_{D}$, 
2. $R_{L}<(1-k) R_{D}$ and $r<(1-k) R_{D}$.

Whenever a positive return $r$ is realized at the middle date, the bank will never default after the stochastic return $\tilde{R}_{2}$ is realized. On the other hand, if $\tilde{R}_{1}=0$, the bank needs to obtain $R_{H}$ at the final date in order to continue operating. In other words, the bank entity defaults only when the zero return at the middle date and the low return at the final date are realized, which happens with probability $(1-p)(1-m)$. Figure 5 presents the model timeline.

\section{[ Figure 5 here ]}

Finally, to narrow the attention to the most interesting case, that is when the SPV project demand is sufficiently high for the execution of guarantees to increase the sponsor's default probability, the following Assumption is introduced:

Assumption 2: The demand for the SPV project relative to the size of the bank project is significant, such that $\lambda \operatorname{var}\left[\tilde{R}_{S P V}\right] \leq c$, where $\operatorname{var}\left[\tilde{R}_{S P V}\right]$ is the variance of the SPV project returns in the absence of implicit guarantees.

Implicit guarantees. Implicit guarantees represent a promise to pay SPV investors the return $r$ at the middle date, when the SPV's own middle-date return is zero and when the bank entity is successful, which happens in the state $(r, 0)$, with probability $p-\underline{p}$. I do not consider guarantees at the end of the second subperiod, assuming that at the time when depositors are paid out, the regulator carefully watches all BHCs' transactions. Finally, the regulator never bails out a defaulting bank: $q=0$.

By Assumption 1 a positive return at the middle date protects the BHC from default if a low return is realized at the end of the second subperiod. Therefore, for a large guarantee payout at the middle date, the BHC's resources might be insufficient to pay depositors in full when $R_{L}$ is realized at the final date. In such case, the BHC's default probability increases and the guarantees provide a recourse to deposit insurance. Whenever realizing guarantees does not result in the additional default probability, the guarantees provide a recourse to bank capital only.

Figure 6 shows all possible end-of-period outcomes when guarantees provide a recourse to bank capital, and when they provide a recourse to deposit insurance.

[ Figure 6 here ]

Lemma 7 summarizes the most important results from the two-stage model. All possible equilibria are presented in Appendix D. 
Lemma 7. For the minimum capital requirement high enough, $k \geq \overline{\bar{k}}$, the recourse to bank capital only is not feasible and the implicit guarantees provide the recourse to deposit insurance. The representative $B H C$ decides to offer guarantees whenever the ex post execution condition holds:

1. when full guarantee repayments are feasible:

$$
(1-m) X_{B}^{r e c}\left(r+R_{L}-(1-k) R_{D}\right)+r m X_{I}^{r e c}<\beta\left(m V^{r e c}-V^{n r}\right)
$$

2. with partial guarantee repayments:

$$
r X_{B}^{r e c}+(1-m)\left(R_{L}-(1-k) R_{D}\right) X_{B}^{r e c}<\beta\left(m V^{r e c}-V^{n r}\right)
$$

Whenever the minimum capital requirement is high enough, execution of guarantees implies increasing the bank's default probability (from zero to $(1-m)$ ). As Lemma 7 makes clear, guarantees with a recourse to deposit insurance can be granted in equilibrium also in the absence of bank bailouts, as long as the ex post execution condition holds. In particular, the BHC is willing to grant the guarantees as long as the additional default probability $(1-m)$ is relatively small.

\subsection{Numerical example}

Figures 7, 8, and 9 present the bank investment, the SPV investment, and the ex post execution condition (a) in the absence of implicit guarantees, and (b) in the presence of implicit guarantees for a parametrized model from Section 7.2. For the chosen parameter values the implicit guarantees always provide a recourse to deposit insurance and only partial repayments are feasible $\left(X_{B}^{\mathrm{rec}}<X_{S P V}^{\mathrm{rec}}\right)$.

Figure 7 shows results for different values of the minimum capital requirement $k$.

\section{[ Figure 7 here ]}

As expected, the bank investment always decreases in $k$. The project intermediation through the SPV is independent of $k$ in the absence of implicit guarantees and is slowly decreasing in $k$ in the presence of implicit guarantees. While a high minimum capital requirement contributes to the emergence of the relationship between bank and SPV investments under implicit guarnatees, it also reduces the value of guarantees to investors. As high $k$ decreases the bank size, the value of guarantees falls, reducing the demand for SPV projects. Nevertheless, in the presence of implicit guarantees the bank investment size always exceeds the bank size optimal in the absence of implicit guarantees. Together with higher SPV project intermediation, this implies an increase in the overall amount of investment in the economy in comparison to the "no recourse" case. 
The last subplot in Figure 7 shows the guarantee execution condition: the indicator function takes the value of 1 if the condition is satisfied, and is equal 0 otherwise. As the plot shows, the execution condition is satisfied for all values of $k$ and the implicit guarantees are always granted in equilibrium.

Figure 8 presents the same results for different values of the investors' risk-aversion parameter $\lambda$. The higher $\lambda$ is, the more risk-averse are investors.

\section{[ Figure 8 here ]}

The size of the bank investment does not depend on $\lambda$ when no guarantees are offered, and is decreasing in $\lambda$ in the presence of guarantees. Highly risk-averse investors have a relatively low demand for the SPV project. Under the dependence of SPV investments on the bank investment that emerges for partial guarantee repayments, BHCs will have lower incentives to raise bank lending for high values of $\lambda$, as the SPV loan demand will increase by less in response to this action, the higher is $\lambda$.

The execution of implicit guarantees is the equilibrium strategy only for $\lambda$ high enough. Thus, for low values of $\lambda$ no guarantees will be granted in equilibrium. Intuitively, when investors are not very risk-averse (low $\lambda$ ), granting implicit guarantees has only little impact on their SPV project demand, as the reduction in the variance of returns does not matter much. As a result, for low $\lambda$, implicit guarantees boost SPV fee income by too little in comparison to the expected costs of repaying guarantees for the $\mathrm{BHCs}$, and the ex post execution condition is not satisfied.

Figure 9 presents results for different values of the BHC bargaining power $\gamma$. Higher $\gamma$ increases the intermediation fee charged by the SPV and thus raises the profitability of off-balance intermediation for the sponsoring BHC.

[ Figure 9 here ]

In the absence of guarantees the bank investment does not change with the BHC bargaining power, because the SPV project demand and the intermediation fee are independent of the BHCs' decisions (Lemma 6). However, once guarantees are granted, the bank investment increases in $\gamma$. Higher bargaining power in the SPV market implies larger incentives for the BHCs to raise the bank investment in order to increase the SPV fee income. Counter-intuitively, the SPV investment is also increasing in $\gamma$. While by Lemma 6 the SPV project demand does not depend on $\gamma$ directly, it does depend on $\gamma$ indirectly under implicit guarantees: higher $\gamma$ increases the profitability of off-balance project intermediation for BHCs and motivates them to raise bank investment to boost the SPV 
project demand. As higher bank investment increases the value of implicit guarantees to investors, the demand for the SPV project eventually increases too.

\section{Concluding remarks}

This paper attempts to explain the incentives of financial intermediaries to set up off-balance vehicles, and to provide them with implicit recourse guarantees. In the model, SPVs are created to satisfy excess demand for risky projects in the presence of costly capital requirements, while implicit guarantees are a tool to increase the fee income from off-balance project intermediation. In the presence of implicit guarantees and for high demand for safe financial assets, the off-balance investment depends on the bank investment decisions. In equilibrium banks supporting SPVs invest more themselves, internalizing the positive effect on SPV fee income. This mechanism potentially increases the total amount of credit in the economy.

Although the guarantees to off-balance vehicles encourage monitoring of sold projects, they might discourage BHCs from screening on-balance projects. Guarantees twist risk-taking incentives of financial intermediaries in the sense that under implicit guarantees monitoring of on-balance projects depends on the profitability of off-balance intermediation.

The model captures two important issues related to financial regulation. First, ex post regulatory policies affect ex ante decisions. In the model, a high bailout probability makes the recourse to deposit insurance more attractive to sponsoring BHCs. Second, there is another negative feedback from regulation: attempts to control more closely and regulate more strictly increase relative attractiveness new forms of economic activity, that are not subject to the existing rules any more. In the model high capital requirements increase the relative profitability of shadow banking activities and contribute to the emergence of a relationship between the bank and the SPV investment.

Nevertheless, strict regulation is often desirable. This is especially the case in the financial sector, vulnerable to a range of potential market failures, such as information asymmetries, moral hazard issues, or free-riding problems. The challenges faced by regulators of financial intermediaries are difficult also due to the role of the latter as "institutions of public trust" and in the presence of integrated capital markets. The ultimate goal of this paper is to provide some insight into the mechanisms through which the regulations are bypassed, and into the issues that need to be considered when designing new financial regulations. Only rules created with the full understanding of the economic interest they control and the economic incentives they stimulate, can make the financial system more transparent and safe. 


\section{References}

Acharya, V. V., 2003, Is the international convergence of capital adequacy regulation desirable?, The Journal of Finance 58, 2745-2782.

— P. Schnabl, and G. Suarez, 2013, Securitization without risk transfer, Journal of Financial Economics 107, 515 - 536.

Acharya, Viral V., and Tanju Yorulmazer, 2008, Cash-in-the-market pricing and optimal resolution of bank failures, Review of Financial Studies 21, 2705-2742.

Altunbas, Y., L. Gambacorta, and D. Marques-Ibanez, 2009, Securitisation and the bank lending channel, European Economic Review 53, 996 - 1009.

Arteta, C., M. Carrey, R. Correa, and J. Kotter, 2013, Revenge of the streamroller: ABCP as a window on risk choices, FRB International Finance Discussion Paper $10^{76}$ FRB International Finance Discussion Paper no. 1076, 2013.

Benveniste, L.M., and A. N. Berger, 1987, Securitization with recourse: An instrument that offers uninsured bank depositors sequential claims, Journal of Banking \& Finance 11, 403 - 424.

BIS, 2012, Revisions to the basel securitisation framework, Basel Committee on Banking Supervision Consultative Document December.

Brunnermeier, M. K., and M. Oehmnke, 2013, The maturity rat race, The Journal of Finance 68, $483-521$.

Coval, J., J. Jurek, and E. Stafford, 2009, The economics of structured finance, The Journal of Economic Perspectives 23, pp. 3-26.

Dell'Ariccia, G., I. Deniz, and L. Laeven, 2012, Credit booms and lending standards: Evidence from the subprime mortgage market, Journal of Money, Credit and Banking 44, 367-384.

DeMarzo, P. M., 2005, The pooling and tranching of securities: A model of informed intermediation, Review of Financial Studies 18, 1-35.

Dewatripont, Mathias, and Xavier Freixas, 2011, Bank resolution: a framework for the assessment of regulatory intervention, Oxford Review of Economic Policy 27, 411-436.

Gennaioli, N., A. Shleifer, and R. W. Vishny, 2013, A model of shadow banking, The Journal of Finance 68, 1331-1363. 
Gilliam, L., 2005, Accounting consolidation versus capital calculation: The conflict over asset-backed commercial paper programs., North Carolina Banking Institute Journal 9, 291-315.

Gorton, Gary, Stefan Lewellen, and Andrew Metrick, 2012, The safe-asset share, American Economic Review 102, 101-06.

Gorton, G., and A. Metrick, 2010, Regulating the shadow banking system, Brookings Papers on Economic Activity 1, 261-312.

— 2012, Securitized banking and the run on repo, Journal of Financial Economics 104, 425 451 Market Institutions, Financial Market Risks and Financial Crisis.

Gorton, G., and G. Pennacchi, 1990, Financial intermediaries and liquidity creation, The Journal of Finance 45, 49-71.

Gorton, G., and N. Souleles, 2007, The Risks of Financial Institutions . chap. Special Purpose Vehicles and Securitization, pp. 549-602 (University of Chicago Press).

Greenbaum, S. I., and A. V. Thakor, 1987, Bank funding modes: Securitization versus deposits, Journal of Banking \& Finance 11, 379 - 401.

Higgins, E., and J. Mason, 2003, What is the value of recourse to asset backed securities? a clinical study of credit card banks., Federal Reserve Bank of Philadelphia Working Paper no. 03-6.

Holmstrom, B., and J. Tirole, 1997, Financial intermediation, loanable funds, and the real sector, The Quarterly Journal of Economics 112, 663-691.

Köhler, Matthias, 2012, Which banks are more risky? the impact of business models on bank stability, Deutsche Bundesbank Working Paper No. 33.

Klee, K., and B. Butler, 2002, Asset-backed securitization, special purpose vehicles and other securitization issues., Uniform Commercial Code Law Journal 35, 23-67.

Mian, A., and A. Sufi, 2009, The consequences of mortgage credit expansion: Evidence from the u.s. mortgage default crisis, The Quarterly Journal of Economics 124, 1449-1496.

Ordoñez, G., 2013, Confidence banking and strategic default, University of Pennsylvania, working paper working paper, University of Pennsylvania, 2013.

Pozsar, Z., T. Adrian, A. Ashcraft, and H. Boesky, 2010, Shadow banking, Federal Reserve Bank of New York Staff Report no. 458. 
Segura, A., 2013, Why did sponsor banks rescue their SIVs? a reputational model of rescues., CEMFI, working paper. 


\section{Appendix}

\section{A Notation summary}

Model parameters with definitions

\begin{tabular}{ll}
\hline Variable or parameter & Definition \\
\hline$X_{B}$ & size of the bank's investment in the risky project \\
$X_{I}$ & individual investor's demand for the SPV project \\
$X_{S P V}=\int_{0}^{1} X_{I}^{i} d i$ & total project size intermediated by a single SPV \\
$K$ & common equity in the bank entity \\
$\delta$ & cost of raising equity \\
$k$ & minimum capital requirement for the bank entity \\
$D$ & deposit base in the bank entity, equal to $(1-k) X_{B}$ \\
$c$ & bank maintenance cost parameter \\
$\lambda$ & risk aversion of investors \\
$\tilde{R}=\{R, 0\}$ & project returns \\
$R_{D}$ & deposit interest rate \\
$s$ & fee charged by the SPV per unit of the project intermediated \\
$p$ & bank project success probability, $p \in\left\{p_{L}, p_{H}\right\}$, with $p_{L}<p_{H}$ \\
$\underline{p}$ & SPV project success probability, $\underline{p} \in\left\{\underline{p}_{L}, \underline{p_{H}}\right\}$, with $\underline{p}_{L}<\underline{p}_{H}$ \\
$C$ & cost of monitoring per uniot of investment \\
$q$ & bailout probability, conditional on bank default \\
$\beta$ & discount factor \\
$\phi$ & fraction of large banks when bank size heterogeneity is introduced \\
\hline
\end{tabular}

\section{B SPVs and implicit guarantees prior to and during the great financial crisis.}

Higgins and Mason (2003) investigate 17 implicit recourse events that happened in the credit card securitization market in the period 1987-2001. In two cases the associated sponsors, Republic Bank and Southeast Bank, entered a default, having repaid SPV investors full principal in the early amortization process prior to the default event. Further, they distinguish between alternative recourse schemes. Through the early amortization the sponsor agrees to make principal payments to conduit investors earlier than planned whenever the underlying pool of conduit assets worsens performance and the portfolio yield falls. In early amortization, the sponsor effectively takes the 
previously securitized assets back on its balance sheet. Alternatively, the sponsor can provide investors with what is called "implicit recourse", in which case there is a transfer of funds from the sponsor to the off-balance vehicle without any asset transfer.

Regarding the period of the recent financial crisis, Acharya, Schnabl, and Suarez (2013) study the special purpose vehicles in the asset-backed commercial paper market (ABCP). They write: “... regulatory arbitrage was the main motive behind setting up conduits: the guarantees were structured so as to reduce regulatory capital requirements, more so by banks with less capital, and while still providing recourse to bank balance sheets for outside investors. Consistent with such recourse, we find that conduits provided little risk transfer during the "run": losses from conduits remained with banks rather than outside investors and banks with more exposure to conduits had lower stock returns."

They show that despite significant losses experienced by the ABCP conduits, all investors in conduits with strong credit guarantees were repaid in full, while investors in conduits with weak credit guarantees suffered only small losses. In total, only $2.5 \%$ of asset-backed commercial paper outstanding as of July 2007 entered default (i.e. stopped repaying investors) in the period from July 2007 to December 2008. As Coval, Jurek, and Stafford (2009) report, only in 2007 Moody's downgraded 31 percent of all tranches for asset-backed collaterized debt obligations it had rated and 14 percent of those initially AAA-rated. Moreover, the realized default rates for structured securities significantly exceeded their historical averages in all rating brackets in the same period (source: Standard and Poor's):

\begin{tabular}{|l|l|l|l|l|l|l|l|l|l|l|l|}
\hline Default rate $(\%)$ & 2001 & 2002 & 2003 & 2004 & 2005 & 2006 & 2007 & 2008 & 2009 & 2010 & 2011 \\
\hline AAA & 0.05 & 0 & 0 & 0 & 0 & 0 & 0.04 & 0.54 & 0.3 & 0.28 & 0.19 \\
\hline Investment grade & 0.1 & 0.12 & 0.12 & 0.04 & 0.02 & 0.02 & 0.22 & 1.04 & 2.63 & 0.81 & 0.22 \\
\hline Speculative grade & 2.75 & 5.7 & 4.2 & 2.29 & 1.79 & 1.3 & 3.09 & 16.09 & 38.53 & 20.14 & 22.8 \\
\hline
\end{tabular}

In many cases SPV rescues lead to serious problems of the sponsoring institutions. In summer 2007 the German banks Sachsen LB and Deutsche Industriebank were bailed out by authorities and then sold after they suffered mass losses in the ABCP vehicles it sponsored. In the U.S., the world largest ABCP sponsor Citigroup was bailed out in November 2008, followed by the bailout of Bank of America - another large ABCP conduit sponsor in early 2009. Citigroup decided to bring $\$ 49$ billion of its SPVs' assets and liabilities onto its own balance sheet in December 2007. In general, the execution of SPV support by sponsors was backed by the U.S. authorities fearing potential runs and fire-sales if sponsors decided to halt repaying SPV investors.

Apart from providing non-contractible - and thus implicit - guarantees, sponsoring institutions also used legal loopholes to provide protection to their SPVs at the lowest capital cost. The existence 
of such loopholes was recognized in the accounting and legal literature prior to the crisis, see e.g. Klee and Butler (2002). For example, the liquidity guarantees widely used by sponsoring banks prior to the crisis were so popular as - contrary to direct credit guarantees - under liquidity guarantee moving a portfolio of loans off the balance was still recognized as a "true sale" of assets, which additionally reduced the amount of required minimum capital for the sponsoring bank (Gilliam (2005)). In particular, under Basel II only a $20 \%$ or a $50 \%$ capital weight applied to liquidity lines provided by sponsors, in comparison to a full $100 \%$ charge for credit guarantees. Yet, as Acharya, Schnabl, and Suarez (2013) argue, liquidity guarantees provided the short-term wholesale investors with the same protection as the credit guarantees would.

An alternative SPV protection mechanism allowing for regulatory arbitrage was the early amortization procedure: an early payment of principal to investors triggered whenever proceeds from the SPV loan portfolio fall below a certain threshold. While the cost of early payouts was effectively borne by the SPV sponsor, early amortization procedure did not require recognition of SPV assets on the sponsor's balance sheet.

The currently discussed changes to the regulatory framework - known as Basel III - include a call to eliminate the favourable treatment of liquidity lines. Basel III also requires all entities

enjoying the early amortization support to be recognized on the supporting institution's balance sheet (BIS (2012)).

\section{Proofs of results}

\section{Lemma 4}

Proof. The BHC monitors the on-balance project when the expected profits from bank activity under monitoring minus the monitoring cost are higher than in the absence of monitoring. Using that the bank investment size does not depend on the monitoring decision, the following condition needs to hold for the BHC to monitor:

$$
\begin{gathered}
p_{H}\left(R-(1-k) R_{D}\right) X_{B}-c X_{B}^{2}-\delta k X_{B}-C X_{B}+\left(p_{H}+\left(1-p_{H}\right) q\right) \beta V^{\mathrm{nr}} \\
\geq p_{L}\left(R-(1-k) R_{D}\right) X_{B}-c X_{B}^{2}-\delta k X_{B}+\left(p_{L}+\left(1-p_{L}\right) q\right) \beta V^{\mathrm{nr}}
\end{gathered}
$$

which can be simplified, and rewritten as a condition for the monitoring $\operatorname{cost} C$ :

$$
C \leq\left(p_{H}-p_{L}\right)\left[\left(R-(1-k) R_{D}\right)+(1-q) \frac{\beta V^{\mathrm{nr}}}{X_{B}}\right]=\bar{C}
$$


The BHC never monitors the sold SPV project, because the BHC does not have the residual interest in the project.

\section{Lemma 1}

Proof. Whenever $X_{B}>X_{S P V}^{\mathrm{rec}}$, the investor's SPV project demand $X_{I}^{\mathrm{rec}}$ in (7) does not depend on $X_{B}$. For the opposite case, $X_{B} \leq X_{S P V}^{\mathrm{rec}}$, we have:

$$
\frac{d X_{I}^{\mathrm{rec}}}{d X_{B}}=\frac{2 \lambda \operatorname{var}\left[\tilde{R}_{S P V}^{\mathrm{rec}}\right](p-\underline{p}) \frac{R}{X_{S P V}^{\mathrm{rec}}}-\frac{d \operatorname{var}\left[\tilde{R}_{S P V}^{\mathrm{rec}}\right]}{d X_{B}}\left(\underline{p} R+(p-\underline{p}) \frac{R X_{B}}{X_{S P V}^{\mathrm{rec}}}-1-s\right)}{4 \lambda^{2} \operatorname{var}^{2}\left[\tilde{R}_{S P V}^{\mathrm{rec}}\right]}
$$

The variance $\operatorname{var}\left[\tilde{R}^{\mathrm{rec}}\right]$ and its derivative with respect to $X_{B}$ are equal:

$$
\begin{aligned}
\operatorname{var}\left[\tilde{R}_{S P V}^{\mathrm{rec}}\right]= & R^{2} \underline{p}(1-\underline{p})+\left(\frac{R X_{B}}{X_{S P V}^{\mathrm{rec}}}\right)^{2}(p-\underline{p})(1-p+\underline{p})-2 R\left(\frac{R X_{B}}{X_{S P V}^{\mathrm{rec}}}\right) \underline{p}(p-\underline{p}) \\
& \frac{d \operatorname{var}\left[\tilde{R}^{\mathrm{rec}}\right]}{d X_{B}}=(p-\underline{p})(1-p+\underline{p}) \frac{2 R^{2} X_{B}}{\left(X_{S P V}^{\mathrm{rec}}\right)^{2}}-\underline{p}(p-\underline{p}) \frac{2 R^{2}}{X_{S P V}^{\mathrm{rec}}}
\end{aligned}
$$

Substituting $\frac{d \operatorname{var}\left[\tilde{R}^{\mathrm{rec}}\right]}{d X_{B}}$ in (36) and simplifying yields:

$$
\begin{aligned}
\frac{d X_{I}^{\mathrm{rec}}}{d X_{B}}= & \frac{(p-\underline{p}) \frac{R^{2}}{X_{S P V}^{\mathrm{rec}}}}{2 \lambda \operatorname{var}^{2}\left[\tilde{R}_{S P V}^{\mathrm{rec}}\right]}\left[\underline{p}(1-\underline{p}) R-(p-\underline{p})(1-p+\underline{p}) R\left(\frac{X_{B}}{X_{S P V}^{\mathrm{rec}}}\right)^{2}-\right. \\
& \left.2(\underline{p} R-1-s)(1-p+\underline{p}) \frac{X_{B}}{X_{S P V}^{\mathrm{rec}}}+2 \underline{p}(\underline{p} R-1-s)\right]
\end{aligned}
$$

The derivative is always positive if the the term in squared parentheses on the RHS of (39) is positive. The term in parentheses has the lowest value for $X_{B}=X_{S P V}^{\mathrm{rec}}$, in which case it is equal to:

$$
\begin{gathered}
\underline{p}(1-\underline{p}) R-(p-\underline{p})(1-p+\underline{p}) R-2(\underline{p} R-1-s)(1-p+\underline{p})+2 \underline{p}(\underline{p} R-1-s)= \\
{[\underline{p}(1-p) R-(p-\underline{p}) R(1-p)-2(\underline{p} R-1-s)(1-p)]=} \\
(1-p)[2(1+s)-p R]
\end{gathered}
$$

which is positive as long as $p R \leq 2$ for a positive $s$.

\section{Lemma 2}


Proof. The bank's own capacity to satisfy guarantees decreases in $k$ if:

$$
\begin{gathered}
\frac{d\left(R-(1-k) R_{D}\right) X_{B}^{\mathrm{nr}}}{d k}<0 \Leftrightarrow \\
\left(R-R_{D}\right)\left(2 p R_{D}-\delta\right)+2 k R_{D}\left(p R_{D}-\delta\right)<0 \Leftrightarrow \\
k>\frac{\left(R-R_{D}\right)\left(2 p R_{D}-\delta\right)}{2 R_{D}\left(\delta-p R_{D}\right)}=k^{*}
\end{gathered}
$$

\section{Proposition 1}

Proof. Case (1): recourse to bank capital. As guarantees are always repaid in full, the individual SPV project demand is equal to:

$$
X_{I}^{\mathrm{rec}}=\frac{p R-1-s}{2 \lambda p(1-p) R^{2}}
$$

The bank is equal to the "no recourse" value $X_{B}^{\mathrm{nr}}$ given by (3). The pair $\left(X_{B}^{\mathrm{nr}}, X_{I}^{\mathrm{rec}}\right)$ is feasible in equilibrium only if $R X_{S P V}^{\mathrm{rec}}<X_{B}^{\mathrm{nr}}\left(R-(1-k) R_{D}\right)$. Using the fact that in equilibrium $X_{S P V}^{\mathrm{rec}}=X_{I}^{\mathrm{rec}}$ this yields the following condition:

$$
\begin{gathered}
R X_{S P V}^{\mathrm{rec}}<X_{B}^{\mathrm{nr}}\left(R-(1-k) R_{D}\right) \Leftrightarrow \\
\frac{R(p R-1-s)}{2 \lambda p(1-p) R^{2}}<\frac{\left[p\left(R-(1-k) R_{D}\right)-\delta k\right]\left(R-(1-k) R_{D}\right)}{2 c}
\end{gathered}
$$

which can be rewritten as:

$$
R_{D}\left(\delta-p R_{D}\right) k^{2}-\left(R-R_{D}\right)\left(2 p R_{D}-\delta\right) k+A<0
$$

with

$$
A=\frac{c(p R-1-s)}{\lambda p(1-p) R}-p\left(R-R_{D}\right)^{2}
$$

The solutions quadratic equation (41) are given by:

$$
\bar{k}_{1}^{1,2}=\frac{\left(R-R_{D}\right)\left(2 p R_{D}-\delta\right)+/-\sqrt{\Delta}}{2 R_{D}\left(\delta-p R_{D}\right)}
$$

with

$$
\Delta=\left(R-R_{D}\right)^{2}\left(2 p R_{D}-\delta\right)^{2}-4 R_{D}\left(\delta-p R_{D}\right) A
$$


There is only one positive threshold $\bar{k}_{1}$ if the following condition holds:

$$
\lambda \geq \frac{c(p R-1-s)}{p^{2}(1-p) R\left(R-R_{D}\right)^{2}}=\tilde{\lambda}
$$

As $\bar{k}_{1}>k^{*}$, this is the only relevant capital requirement threshold as long as $k>k^{*}$.

Case (2): recourse to deposit insurance with full guarantee repayments. The individual demand for the SPV project is again equal to (40). The bank investment size is:

$$
X_{B}^{\mathrm{rec}}=\frac{\underline{p}\left(R-(1-k) R_{D}\right)-\delta k}{2 c}<X_{B}^{\mathrm{nr}}
$$

The new pair $\left(X_{B}^{\mathrm{rec}}, X_{I}^{\mathrm{rec}}\right)$ is feasible in equilibrium if:

$$
\begin{gathered}
R X_{S P V}^{\mathrm{rec}}<R X_{B}^{\mathrm{rec}} \Leftrightarrow \\
\frac{p R-1-s}{2 \lambda p(1-p) R^{2}} \leq \frac{\underline{p}\left(R-(1-k) R_{D}\right)-\delta k}{2 c} \Leftrightarrow \\
k \leq \frac{\underline{p}\left(R-R_{D}\right)-\frac{c(p R-1-s)}{\lambda p(1-p) R^{2}}}{\delta-\underline{p} R_{D}}=\bar{k}_{2}
\end{gathered}
$$

Case (3): : recourse to deposit insurance with partial guarantee repayments. The SPV investment size depends on the bank investment $\left(\frac{d X_{I}^{\text {rec }}}{d X_{B}}>0\right)$, and the pair $\left(X_{B}^{\text {rec }}, X_{I}^{\text {rec }}\right)$ is implicitly given by the following conditions:

1. The representative investor's SPV project demand is equal:

$$
X_{I}^{\mathrm{rec}}=\frac{\underline{p} R+(p-\underline{p}) \frac{R X_{B}^{\mathrm{rec}}}{X_{S P V}^{\mathrm{rec}}}-1-s}{2 \lambda \operatorname{var}\left[\tilde{R}_{S P V}^{\mathrm{rec}}\right]}>X_{I}^{n r}
$$

2. The representative BHC's bank investment $X_{B}^{\text {rec }}$ solves:

$$
\max _{X_{B}}\left[s X_{S P V}^{\mathrm{rec}}\left(X_{B}\right)+\underline{p}\left(R-(1-k) R_{D}\right) X_{B}-c\left(X_{B}\right)^{2}-\delta k X_{B}+\beta(\underline{p}+(1-\underline{p}) q) V^{\mathrm{rec}}\right]
$$

3. In equilibrium $X_{I}^{\mathrm{rec}}=X_{S P V}^{\mathrm{rec}}$.

where $\operatorname{var}\left[\tilde{R}_{S P V}^{\mathrm{rec}}\right]$ is given in (37).

\section{Lemma 3}


Proof. Using that in equilibrium $X_{I}^{\mathrm{rec}}=X_{S P V}^{\mathrm{rec}}$ and subsitituting formula (37) for the variance $\operatorname{var}\left[\tilde{R}_{S P V}^{\text {rec }}\right]$, the equation (13) can be rewritten as a quadratic equation:

$$
\begin{gathered}
2 \lambda R^{2} \underline{p}(1-\underline{p})\left(X_{I}^{\mathrm{rec}}\right)^{2}-\left[4 \lambda r^{2} \underline{p}(1-\underline{p}) X_{B}-(\underline{p} R-1-s)\right] X_{I}^{\mathrm{rec}} \\
+2 \lambda(p-\underline{p})(1-p+\underline{p})\left(R X_{B}\right)^{2}-(p-\underline{p}) R X_{B}
\end{gathered}
$$

which has two solutions:

$$
\begin{gathered}
X_{I}^{\mathrm{rec}}=\frac{\left[4 \lambda R^{2} \underline{p}(p-\underline{p}) X_{B}-(\underline{p} R-1-s)\right] \pm \sqrt{\Delta}}{4 \lambda R^{2} \underline{p}(1-\underline{p})} \\
\Delta=\left[4 \lambda R^{2} \underline{p}(p-\underline{p}) X_{B}-(\underline{p} R-1-s)\right]^{2}-8 \lambda R^{2} \underline{p}(1-\underline{p})\left[R X_{B}(p-\underline{p})\left(2 \lambda(1-p+\underline{p}) R X_{B}-1\right)\right]
\end{gathered}
$$

There is only one positive solution to (43) if and only if the following condition holds:

$$
\begin{gathered}
2 \lambda(1-p+\underline{p}) R X_{B}-1<0 \Leftrightarrow \\
\lambda<\frac{1}{2(1-p+\underline{p}) X_{B}}
\end{gathered}
$$

The minimum equilibrium value of $X_{B}$ is given by the formula (12). Substituting yields:

$$
\lambda<\frac{c}{(1-p+\underline{p}) R\left(\underline{p}\left(R-(1-k) R_{D}\right)-\delta k\right)}=\hat{\lambda}
$$

The equilibrium individual investor's demand is then given by:

$$
X_{I}^{\mathrm{rec}}=\frac{\left[4 \lambda R^{2} \underline{p}(p-\underline{p}) X_{B}-(\underline{p} R-1-s)\right]+\sqrt{\Delta}}{4 \lambda R^{2} \underline{p}(1-\underline{p})}
$$

and the bank investment is the solution to the first order condition:

$$
\left.\underline{p}\left(R-(1-k) R_{D}\right)\right)-\delta k+s \frac{d X_{I}^{\mathrm{rec}}}{d X_{B}}=2 c X_{B}
$$


The derivative $\frac{d X_{I}^{\mathrm{rec}}}{d X_{B}}$ is equal to:

$$
\begin{aligned}
\frac{d X_{I}^{\mathrm{rec}}}{d X_{B}} & =\frac{p-\underline{p}}{1-\underline{p}}+\frac{(p-\underline{p})\left[4 \lambda R^{2} \underline{p}(p-\underline{p}) X_{B}-(\underline{p} R-1-s)+(1-\underline{p}) R\left(1-2 \lambda(1-p+\underline{p}) R X_{B}\right)\right]}{(1-\underline{p}) \sqrt{\Delta}} \\
& =\frac{p-\underline{p}}{1-\underline{p}}(1+\underbrace{\frac{\left[4 \lambda R^{2} \underline{p}(p-\underline{p}) X_{B}-(\underline{p} R-1-s)+(1-\underline{p}) R\left(1-2 \lambda(1-p+\underline{p}) R X_{B}\right)\right]}{\sqrt{\Delta}}}_{=\mathrm{D}})
\end{aligned}
$$

The term $D$ and thus the whole derivative are positive as long as $\lambda<\hat{\lambda}$.

The first order condition (45) allows for multiple solutions. For a given solution to (45) to be higher than $X_{B}^{\mathrm{nr}}$ (the bank investment in absence of implicit guarantees), the following condition needs to hold:

$$
\begin{gathered}
\left.\left.\underline{p}\left(R-(1-k) R_{D}\right)\right)-\delta k+\frac{p-\underline{p}}{1-\underline{p}}(1+D)>p\left(R-(1-k) R_{D}\right)\right)-\delta k \Leftrightarrow \\
\left.\frac{p-\underline{p}}{1-\underline{p}}(1+D)>(p-\underline{p})\left(R-(1-k) R_{D}\right)\right) \Leftrightarrow \\
\left.\frac{1+D}{1-\underline{p}}>\left(R-(1-k) R_{D}\right)\right)
\end{gathered}
$$

which always holds as long as $D$ is positive and $R-(1-k) R_{D}<1$.

\section{Proposition 2}

Proof. Under the recourse to bank capital, the ex post execution condition is:

$$
\begin{gathered}
\beta V^{\mathrm{rec}}-R X_{S P V}^{\mathrm{rec}} \geq \beta V^{\mathrm{nr}} \Leftrightarrow \\
R X_{S P V}^{\mathrm{rec}} \leq \beta\left(V^{\mathrm{rec}}-V^{\mathrm{nr}}\right) \Leftrightarrow \\
R X_{S P V}^{\mathrm{rec}} \leq \frac{\beta s\left(X_{S P V}^{\mathrm{rec}}-X_{S P V}^{\mathrm{nr}}\right)}{1-\beta(p+(1-p) q)}
\end{gathered}
$$

For the recourse to deposit insurance, the probability of bankruptcy after the execution of guarantees 
is $1-q$ and has to be accounted for:

$$
\begin{gathered}
q \beta V^{\mathrm{rec}}-\left(R-(1-k) R_{D}\right) X_{B}^{\mathrm{rec}} \geq \beta V^{\mathrm{nr}} \Leftrightarrow \\
\left(R-(1-k) R_{D}\right) X_{B}^{\mathrm{rec}} \leq \beta\left(q V^{\mathrm{rec}}-V^{\mathrm{nr}}\right)
\end{gathered}
$$

\section{Corollary 1}

Proof. Immediate mathematic calculation.

\section{Lemma 5}

Proof. The monitoring decisions of the BHCs are considered for the recourse to bank capital and for the recourse to deposit insurance separately.

Monitoring under recourse to bank capital. If guarantees provide a recourse to bank capital only, the probability of bank default does not change when guarantees are executed. Moreover, the monitoring of the SPV project does not influence the demand for the SPV project, which is always equal to

$$
X_{S P V}=\frac{p R-1-s}{2 \lambda p(1-p) R^{2}}
$$

In particular, term $p$ represents success probability of the bank project, $p \in\left\{p_{L}, p_{H}\right\}$. The condition for monitoring of the SPV project can be thus written as:

$$
\begin{gathered}
s X_{S P V}+\underline{p}_{H}\left(R-(1-k) R_{D}\right) X_{B}+\left(p-\underline{p}_{H}\right)\left[\left(R-(1-k) R_{D}\right) X_{B}-R X_{S P V}\right]-C X_{S P V} \geq \\
s X_{S P V}+\underline{p}_{L}\left(R-(1-k) R_{D}\right) X_{B}+\left(p-\underline{p}_{L}\right)\left[\left(R-(1-k) R_{D}\right) X_{B}-R X_{S P V}\right] \\
\Leftrightarrow \\
C \leq R\left(\underline{p}_{H}-\underline{p}_{L}\right)=\tilde{C}_{1}
\end{gathered}
$$


The condition for monitoring the bank project is given by:

$$
\begin{gathered}
s X_{S P V}^{\mathrm{m}, \mathrm{b}}+\left(p_{H}-\underline{p}\right)\left[\left(R-(1-k) R_{D}\right) X_{B}-R X_{S P V}^{\mathrm{m}, \mathrm{b}}\right]+\left(p_{H}+\left(1-p_{H}\right) q\right) \beta V^{\mathrm{rec}}-C X_{B} \geq \\
s X_{S P V}^{\mathrm{nm}, \mathrm{b}}+\left(p_{L}-\underline{p}\right)\left[\left(R-(1-k) R_{D}\right) X_{B}-R X_{S P V}^{\mathrm{nm}, \mathrm{b}}\right]+\left(p_{L}+\left(1-p_{L}\right) q\right) \beta V^{\mathrm{rec}} \\
\Leftrightarrow \\
C \leq\left(p_{H}-p_{L}\right)\left[\left(R-(1-k) R_{D}\right)+\frac{(1-q) \beta V^{\mathrm{rec}}}{X_{B}}\right]+ \\
\frac{\left(s+\left(\underline{p}-p_{H}\right) R\right)\left(X_{S P V}^{\mathrm{m}, \mathrm{b}}-X_{S P V}^{\mathrm{nm}, \mathrm{b}}\right)-\left(p_{H}-p_{L}\right) R X_{S P V}^{\mathrm{nm}, \mathrm{b}}}{X_{B}}=\underline{\mathrm{C}}_{1}
\end{gathered}
$$

where $\underline{p}$ represents success probability of the SPV project, $\underline{p} \in\left\{\underline{p}_{L}, \underline{p}_{H}\right\} . X_{S P V}^{\mathrm{m}, \mathrm{b}}$ stands for the SPV project demand under monitoring of the bank project, and $X_{S P V}^{\mathrm{nm}, \mathrm{b}}$ - in the absence of monitoring.

Under the recourse to deposit insurance, the SPV project demand is:

$$
X_{S P V}=\frac{\underline{p} R+\left(p-\underline{p} \frac{R X_{B}}{X_{S P V}}-1-s\right.}{2 \lambda \operatorname{var}\left[\tilde{R}_{S P V}^{r e c}\right]}
$$

with $\operatorname{var}\left[\tilde{R}_{S P V}^{r e c}\right]$ fiven by equation (37). The monitoring condition for the SPV project is then:

$$
\begin{gathered}
s X_{S P V}^{\mathrm{m}}+\underline{p}_{H}\left(R-(1-k) R_{D}\right) X_{B}+\left(\underline{p}_{H}+\left(1-\underline{p}_{H}\right) q\right) \beta V^{\mathrm{rec}}-C X_{S P V}^{\mathrm{m}} \geq \\
s X_{S P V}^{\mathrm{nm}}+\underline{p}_{L}\left(R-(1-k) R_{D}\right) X_{B}+\left(\underline{p}_{L}+\left(1-\underline{p}_{L}\right) q\right) \beta V^{\mathrm{rec}} \\
\Leftrightarrow \\
C \leq \frac{s\left(X_{S P V}^{\mathrm{m}}-X_{S P V}^{\mathrm{nm}}\right)+\left(\underline{p}_{H}-\underline{p}_{L}\right)\left[\left(R-(1-k) R_{D}\right) X_{B}+\beta(1-q) V^{\mathrm{rec}}\right]}{X_{S P V}^{\mathrm{m}}}=\tilde{C}_{2}
\end{gathered}
$$

The monitoring condition for the bank project is:

$$
\begin{gathered}
s X_{S P V}^{\mathrm{m}, \mathrm{b}}-C X_{B} \geq s X_{S P V}^{\mathrm{nm}, \mathrm{b}} \\
\Leftrightarrow \\
C \leq \frac{s\left(X_{S P V}^{\mathrm{m}, \mathrm{b}}-X_{S P V}^{\mathrm{nm}, \mathrm{b}}\right)}{X_{B}}=\underline{\mathrm{C}}_{2}
\end{gathered}
$$

Taking the derivatives of bank project monitoring thresholds with respect to the SPV project success 
probability yields:

$$
\begin{gathered}
\frac{d \underline{\mathrm{C}}_{1}}{d \underline{p}}=\frac{R\left(X_{S P V}^{\mathrm{m}, \mathrm{b}}-X_{S P V}^{\mathrm{nm}, \mathrm{b}}\right)}{X_{B}}>0 \\
\frac{d \underline{\mathrm{C}}_{2}}{d \underline{p}}=\frac{s}{X_{B}}\left(\frac{d\left(X_{S P V}^{\mathrm{m}, \mathrm{b}}\right.}{d \underline{p}}-\frac{d X_{S P V}^{\mathrm{nm}, \mathrm{b}}}{d \underline{p}}\right)
\end{gathered}
$$

For the monitoring threshold under the recourse to deposit insurance two cases have to be distinguished: (1) when full guarantee repayments are feasible, (2) only partial repayments are feasible. Under (1) the SPV project demand does not depend on $\underline{p}$ and the derivative of $\underline{\mathrm{C}}_{2}$ with respect to $\underline{p}$ is equal zero. Under (2) the sign of the derivative $\frac{d \mathrm{C}_{2}}{d \underline{p}}$ is ambiguous.

\section{Proposition 3}

Proof. Both types of BHCs offer implicit guarantees with full repayments when the full repayment is feasible for BHCs with small banks:

$$
\begin{gathered}
R X_{I}^{\mathrm{rec}} \leq R X_{B, S}^{\mathrm{nr}} \Leftrightarrow \\
\frac{(p R-1-s)}{2 \lambda p(1-p) R^{2}} \leq \frac{\underline{p}\left(R-(1-k) R_{D}\right)-\delta k}{2 c_{S}} \Leftrightarrow \\
k \leq \frac{\underline{p}\left(R-R_{D}\right)-\frac{c_{S}(p R-1-s)}{\lambda p(1-p) R^{2}}}{\delta-\underline{p} R_{D}}=\tilde{k}_{1}
\end{gathered}
$$

For $k>\tilde{k}_{1}$ only large BHCs are present in the shadow banking. The demand for their services increases from $X_{I}^{\text {rec }}$ to $\frac{1}{\phi} X_{I}^{\text {rec }}$. The full repayment condition is now:

$$
\begin{gathered}
\frac{R}{\phi} X_{I}^{\mathrm{rec}} \leq R X_{B, L}^{\mathrm{nr}} \Leftrightarrow \\
\frac{(p R-1-s)}{2 \phi \lambda p(1-p) R^{2}} \leq \frac{\underline{p}\left(R-(1-k) R_{D}\right)-\delta k}{2 c_{L}} \Leftrightarrow \\
k \leq \frac{p\left(R-R_{D}\right)-\frac{c_{L}(p R-1-s)}{\phi \lambda p(1-p) R^{2}}}{\delta-\underline{p} R_{D}}=\tilde{k}_{2}
\end{gathered}
$$

which is larger than $\tilde{k}_{1}$ as long as $\frac{c_{L}}{\phi}<c_{S}$. Finally, if $k>\tilde{k}_{2}$ large BHCs are not able to offer guarantees with full repayments. Both types of BHCs are present in the shadow banking, and attract fractions $(\nu, 1-\nu)$ of investors, such that in equilibrium both types of BHCs offer the same 
level of partial guarantee repayments:

$$
\begin{gathered}
X_{I}^{\mathrm{rec}, \mathrm{L}}=X_{I}^{\mathrm{rec}, \mathrm{S}}=X_{I}^{\mathrm{rec}} \Leftrightarrow \\
\frac{R X_{B, L}^{\mathrm{rec}}}{\frac{\nu}{\phi} X_{I}^{\mathrm{rec}}}=\frac{R X_{B, S}^{\mathrm{rec}}}{\frac{(1-\nu)}{(1-\phi)} X_{I}^{\mathrm{rec}}} \Leftrightarrow \\
\frac{(1-\nu)}{(1-\phi)} X_{B, L}^{\mathrm{rec}}=\frac{\nu}{\phi} X_{B, S}^{\mathrm{rec}}
\end{gathered}
$$

\section{Lemma 6}

Proof. Immediate mathematic calculation.

\section{Lemma 7}

Proof. By Assumption 2 the full guarantee repayment under the recourse to bank capital is never feasible (see Appendix D for a formal proof). Under the recourse to deposit insurance, the cost of realizing guarantees is either $r X_{I}^{\mathrm{rec}}$ (full repayment) or $r X_{B}^{\mathrm{rec}}$ (partial repayment). Executing guarantees with a recourse to deposit insurance always increases BHC's default probability. Thus, the ex post execution condition has to correct for the decreased probability of continuation: from 1 to $m$. The execution condition for the full repayment case is:

$$
\begin{gathered}
m\left(\left(R_{H}-(1-k) R_{D}\right) X_{B}^{\mathrm{rec}}+r\left(X_{B}^{\mathrm{rec}}-X_{I}^{\mathrm{rec}}\right)\right)+m \beta V^{\mathrm{rec}}> \\
\left(r+m R_{H}+(1-m) R_{L}-(1-k) R_{D}\right) X_{B}^{\mathrm{rec}}+\beta V^{\mathrm{nr}} \Leftrightarrow \\
(1-m)\left(X_{B}^{\mathrm{rec}}\left[r+R_{L}-(1-k) R_{D}\right]+r m X_{I}^{\mathrm{rec}}<\beta\left(m V^{\mathrm{rec}}-V^{\mathrm{nr}}\right)\right.
\end{gathered}
$$

and for the partial repayment:

$$
\begin{gathered}
m\left(R_{H}-(1-k) R_{D}\right) X_{B}^{\mathrm{rec}}+m \beta V^{\mathrm{rec}}>\left(r+m R_{H}+(1-m) R_{L}-(1-k) R_{D}\right) X_{B}^{\mathrm{rec}}+\beta V^{\mathrm{nr}} \Leftrightarrow \\
r X_{B}^{\mathrm{rec}}+(1-m)\left(R_{L}-(1-k) R_{D}\right) X_{B}^{\mathrm{rec}}<\beta\left(m V^{\mathrm{rec}}-V^{\mathrm{nr}}\right)
\end{gathered}
$$

\section{Proposition 4}

Proof. In the following I use the result from Section 7 the demand for SPV project does not depend on the fee level $s$ is a result of the bargaining process. Keeping $k$ fixed, the net welfare effect of a 
recourse to bank capital is:

$$
\begin{gathered}
\text { Welfare }^{\mathrm{bc}}-\text { Welfare }^{\mathrm{nr}}= \\
(\underline{p} R-1)\left(X_{\mathrm{SPV}}^{\mathrm{full}}-X_{\mathrm{SPV}}^{\mathrm{nr}}\right)-\lambda R^{2}\left(p(1-p)\left(X_{\mathrm{SPV}}^{\mathrm{full}}\right)^{2}-\underline{p}(1-\underline{p})\left(X_{\mathrm{SPV}}^{\mathrm{nr}}\right)^{2}\right)= \\
\frac{1}{2}\left[(2 \underline{p} R-p R-1) X_{\mathrm{SPV}}^{\mathrm{full}}-(\underline{p} R-1) X_{\mathrm{SPV}}^{\mathrm{nr}}\right]= \\
\frac{1}{2} \frac{(p-\underline{p})\left[(2 \underline{p} R-1)(1-\underline{p}-p)+p \underline{p} R^{2}(2 p-1)\right]}{2 \lambda p(1-p) \underline{p}(1-\underline{p}) R^{2}}
\end{gathered}
$$

which is always positive as $\underline{p}+p-1<2 p-1$ and $2 \underline{p} R-1<\underline{p}^{2} R^{2}<p \underline{p} R^{2}$. The upper-script "full" corresponds to full guarantee repayments. The net welfare effect of a recourse to deposit insurance with full repayments is:

$$
\begin{gathered}
\text { Welfare }^{\text {di,full }}-\text { Welfare }^{\mathrm{nr}}= \\
\underbrace{\Delta \mathbb{E} \Pi_{B}+(1-k)\left(X_{B}^{\mathrm{nr}}-X_{B}^{\mathrm{di}, \text { full }}\right)}_{=A_{1}<0}+\underbrace{\frac{1}{2}\left[(\underline{p} R-p R-1) X_{\mathrm{SPV}}^{\mathrm{full}}-(\underline{p} R-1) X_{\mathrm{SPV}}^{\mathrm{nr}}\right]}_{=B>0}+ \\
(F-1)(p-\underline{p})\left[\left(R-(1-k) R_{D}\right)\left(X_{B}^{\mathrm{nr}}+\frac{(1-p) R_{D}(1-k)}{2 c}\right)-R X_{\mathrm{SPV}}^{\mathrm{full}}\right]
\end{gathered}
$$

Two cases follow:

1. The net welfare effect of recourse to deposit insurance is increasing in $F$, and is negative for $F<\frac{B-A_{1}}{(p-\underline{p})\left(R-(1-k) R_{D}\right)\left(X_{B}^{\mathrm{nr}}+\frac{(1-p) R_{D}(1-k)}{2 c}\right)-R X_{\mathrm{SPV}}^{\mathrm{full}}}+1=\tilde{F}_{1}$ when:

$$
\begin{gathered}
\left(R-(1-k) R_{D}\right)\left(X_{B}^{\mathrm{nr}}+\frac{(1-p) R_{D}(1-k)}{2 c}\right)-R X_{\mathrm{SPV}}^{\mathrm{full}}>0 \Leftrightarrow \\
\lambda>\frac{c(p R-1)}{p(1-p) R\left(R-(1-k) R_{D}\right)\left(p R-(2 p-1)(1-k) R_{D}-\delta k\right)}=\hat{\hat{\lambda}}
\end{gathered}
$$

2. The net welfare effect of recourse to deposit insurance is decreasing in $F$, and is negative for $F>\tilde{F}_{1}$ when $\lambda<\hat{\hat{\lambda}}$ Both thresholds $\tilde{F}_{1}$ and $\hat{\hat{\lambda}}$ depend on $k$ in a non-linear way.

To evaluate the net welfare effect of a recourse to deposit insurance with partial guarantee 
repayments, I restrict attention to the case when $\lambda<\hat{\lambda}$ and thus $X_{B}^{\text {di,partial }}>X_{B}^{\mathrm{nr}}$ :

$$
\begin{gathered}
\text { Welfare }^{\text {di,partial }}-\text { Welfare }^{\mathrm{nr}}= \\
\underbrace{\Delta \mathbb{E} \Pi_{B}+(1-k)\left(X_{B}^{\mathrm{nr}}-X_{B}^{\mathrm{di}, \text { partial }}\right)}_{=A_{2}<0}+\underbrace{\frac{1}{2}\left[\left(\underline{p}^{2} R-1\right)\left(X_{\mathrm{SPV}}^{\text {partial }}-X_{\mathrm{SPV}}^{\mathrm{nr}}\right)-(p-\underline{p}) R X_{B}^{\text {di,partial }}\right]}_{=B_{2} \lessgtr 0}- \\
-(F-1)(1-k) R_{D}[\underbrace{(1-\underline{p}) X_{B}^{\text {di,partial }}-(1-p) X_{B}^{\mathrm{nr}}}_{=C>0}]
\end{gathered}
$$

The net welfare effect is always decreasing in $F$ and is negative if:

$$
F>\frac{A_{2}+B_{2}}{(1-k) R_{D}\left[(1-\underline{p}) X_{B}^{\text {di,partial }}-(1-p) X_{B}^{\mathrm{nr}}\right]}+1=\tilde{F}_{2}
$$

which is again a non-linear function of $k$.

\section{Proposition 5}

Proof. I begin with the comparison of welfares under the recourse to bank capital (minimum requirement $\left.k^{\mathrm{bc}}\right)$ and under the recourse to deposit insurance with partial repayments $\left(k^{\mathrm{di}, \mathrm{p}}\right)$. It holds that $k^{\mathrm{bc}}<k^{\mathrm{di}, \mathrm{p}}$ and $\left(1-k^{\mathrm{bc}}\right) X_{B}^{\mathrm{bc}}<\left(1-k^{\mathrm{di}, \mathrm{p}}\right) X_{B}^{\mathrm{di}, \mathrm{p}}$ for $\lambda<\hat{\lambda}$. The comparison yields:

$$
\begin{gathered}
\text { Welfare }^{\mathrm{di}, \mathrm{p}}-\text { Welfare }^{\mathrm{bc}}= \\
\underbrace{\Delta \mathbb{E} \Pi_{B}+\left(\left(1-k^{\mathrm{bc}}\right) X_{B}^{\mathrm{bc}}-\left(1-k^{\mathrm{di}, \mathrm{p}}\right) X_{B}^{\mathrm{di}, \mathrm{p}}\right)}_{<0}+ \\
+\frac{1}{2}\left[\left(\underline{p}^{R}-1\right)\left(X_{\mathrm{SPV}}^{\mathrm{part}}-X_{\mathrm{SPV}}^{\mathrm{full}}\right)-(p-\underline{p})\left(R X_{B}^{\mathrm{di}, \mathrm{p}}-X_{\mathrm{SPV}}^{\mathrm{full}}\right)\right]- \\
-(F-1)\left[(1-\underline{p})\left(1-k^{\mathrm{di}, \mathrm{p}}\right) R_{D} X_{B}^{\mathrm{di}, \mathrm{p}}-(1-p)\left(1-k^{\mathrm{bc}}\right) R_{D} X_{B}^{\mathrm{bc}}\right]
\end{gathered}
$$

The net welfare effect of the recourse to deposit insurance is always decreasing in the fiscal cost $F$, and there exists a threshold fiscal cost $\bar{F}_{1}$ above which the net welfare effect is always negative. The threshold level depends on both $k^{\mathrm{bc}}$ and $k^{\mathrm{di}, \mathrm{p}}$.

Second, consider welfares under the recourse to deposit insurance with full (minimum requirement $\left.k^{\mathrm{di}, \mathrm{f}}\right)$ and with partial repayments $\left(k^{\mathrm{di}, \mathrm{p}}\right)$. It holds that $k^{\mathrm{di}, \mathrm{f}}<k^{\mathrm{di}, \mathrm{p}}$ and $\left(1-k^{\mathrm{di}, \mathrm{f}}\right) X_{B}^{\mathrm{di}, \mathrm{f}}<(1-$ 
$\left.k^{\mathrm{di}, \mathrm{p}}\right) X_{B}^{\mathrm{di}, \mathrm{p}}$ for $\lambda<\hat{\lambda}$. The comparison yields:

$$
\begin{gathered}
\text { Welfare }^{\mathrm{di}, \mathrm{p}}-\text { Welfare }^{\mathrm{di}, \mathrm{f}}= \\
\underbrace{\Delta \mathbb{E} \Pi_{B}+\left(\left(1-k^{\mathrm{di}, \mathrm{f}}\right) X_{B}^{\mathrm{di}, \mathrm{f}}-\left(1-k^{\mathrm{di}, \mathrm{p}}\right) X_{B}^{\mathrm{di}, \mathrm{p}}\right)}_{<0}+ \\
+\frac{1}{2}\left[(\underline{p} R-1)\left(X_{\mathrm{SPV}}^{\mathrm{part}}-X_{\mathrm{SPV}}^{\mathrm{full}}\right)-(p-\underline{p})\left(R X_{B}^{\mathrm{di}, \mathrm{p}}-X_{\mathrm{SPV}}^{\mathrm{full}}\right)\right]- \\
-(F-1)\left[(1-\underline{p})\left(\left(1-k^{\mathrm{di}, \mathrm{p}}\right) R_{D} X_{B}^{\mathrm{di}, \mathrm{p}}-\left(1-k^{\mathrm{di}, \mathrm{f}}\right) R_{D} X_{B}^{\mathrm{di}, \mathrm{f}}\right)+(p-\underline{p}) R\left(X_{B}^{\mathrm{di}, \mathrm{f}}-X_{\mathrm{SPV}}^{\mathrm{full}}\right)\right]
\end{gathered}
$$

which is always decreasing in $F$. There exists a threshold $\bar{F}_{2}$, above which the net welfare effect is always negative for given $k^{\mathrm{bc}}$ and $k^{\mathrm{di}, \mathrm{p}}$.

Finally, consider welfares under the recourse to bank capital (minimum requirement $k^{\mathrm{bc}}$ ) and under the recourse to deposit insurance with full repayments $\left(k^{\mathrm{di}, \mathrm{f}}\right)$. It holds that $k^{\mathrm{bc}}<k^{\mathrm{di}, \mathrm{f}}$ and $\left(1-k^{\mathrm{bc}}\right) X_{B}^{\mathrm{bc}}>\left(1-k^{\mathrm{di}, \mathrm{f}}\right) X_{B}^{\mathrm{di}, \mathrm{f}}$ for all $k>k^{*}$ by Lemma 2 . The comparison yields:

$$
\begin{gathered}
\text { Welfare }^{\text {di,full }}-\text { Welfare }^{\mathrm{bc}}= \\
\underbrace{\Delta \mathbb{E} \Pi_{B}+\left(\left(1-k^{\mathrm{bc}}\right) X_{B}^{\mathrm{bc}}-\left(1-k^{\mathrm{di}, \mathrm{f}}\right) X_{B}^{\mathrm{di}, \mathrm{f}}\right)}_{<0}+ \\
(F-1)\left[(p-\underline{p})\left[\left(R-\left(1-k^{\mathrm{di}, \mathrm{f}}\right) R_{D}\right) X_{B}^{\mathrm{di}, \mathrm{f}}-R X_{\mathrm{SPV}}^{\mathrm{full}}\right]+(1-p) R_{D}\left[\left(1-k^{\mathrm{bc}}\right) X_{B}^{\mathrm{bc}}-\left(1-k^{\mathrm{di}}\right) X_{B}^{\mathrm{di}}\right]\right]
\end{gathered}
$$

The whole expression is always negative if:

$$
\begin{gathered}
(p-\underline{p})\left[R X_{\mathrm{SPV}}^{\mathrm{full}}-\left(R-\left(1-k^{\mathrm{di}, \mathrm{f}}\right) R_{D}\right) X_{B}^{\mathrm{di}, \mathrm{f}}\right]>(1-p) R_{D}\left[\left(1-k^{\mathrm{bc}}\right) X_{B}^{\mathrm{bc}}-\left(1-k^{\mathrm{di}}\right) X_{B}^{\mathrm{di}}\right] \Leftrightarrow \\
\lambda<\frac{(p-\underline{p})(p R-1)}{p(1-p) R\left[(1-p) R_{D}\left[\left(1-k^{\mathrm{bc}}\right) X_{B}^{\mathrm{bc}}-\left(1-k^{\mathrm{di}}\right) X_{B}^{\mathrm{di}}\right]+(p-\underline{p})\left(R-\left(1-k^{\mathrm{di}, \mathrm{f}}\right) R_{D}\right) X_{B}^{\mathrm{di}, \mathrm{f}}\right]}=\underline{\lambda}
\end{gathered}
$$

For $\lambda>\underline{\lambda}$, the net welfare effect is actually decreasing in the fiscal cost $F$. It is straightforward to show that there exists a threshold fiscal cost $\bar{F}_{3}$, below which, a recourse to deposit insurance is preferred to the recourse to bank capital. The thresholds $\underline{\lambda}$ and $\bar{F}_{3}$ are again functions of the chosen capital requirements $k^{\mathrm{bc}}$ and $k^{\mathrm{di}}$. 


\section{Model with two-stage returns and endogenous fee}

SPV project demand. Consider first the demand for the SPV project. If full repayments are possible $\left(r X_{S P V}^{\mathrm{rec}} \leq r X_{B}^{\mathrm{rec}}\right)$, the expected return and the return variance for the SPV project are:

$$
\begin{gathered}
\mathbb{E}\left[\tilde{R}_{S P V}^{r e c, 1}\right]=p r+\mathbb{E}\left[\tilde{R}_{2}\right] \\
\operatorname{var}\left[\tilde{R}_{S P V}^{r e c, 1}\right]=r^{2} p(1-p)+\left(R_{H}-R_{L}\right)^{2} m(1-m)=r^{2} p(1-p)+\operatorname{var}\left[\tilde{R}_{2}\right]
\end{gathered}
$$

The individual investor's project demand satisfying the first order condition (26) is equal to:

$$
X_{I}^{r e c, 1}=\frac{p r+\mathbb{E}\left[\tilde{R}_{2}\right]-1}{2 \lambda \operatorname{var}\left[\tilde{R}_{S P V}^{r e c, 1}\right]}
$$

Under partial repayments $\left(r X_{S P V}^{r e c}>r X_{B}^{\text {rec }}\right)$ the investor receives $\frac{r X_{B}^{\text {rec }}}{X_{S P V}^{r e c}}$ of the promised full repayment. The expected return and return variance for the SPV project are now:

$$
\begin{gathered}
\mathbb{E}\left[\tilde{R}_{S P V}^{r e c, 2}\right]=\underline{p r}+(p-\underline{p}) \frac{r X_{B}^{r e c}}{X_{S P V}^{r e c}}+\mathbb{E}\left[\tilde{R}_{2}\right] \\
\operatorname{var}\left[\tilde{R}_{S P V}^{r e c, 2}\right]=r^{2} \underline{p}(1-\underline{p})+\left(\frac{r X_{B}^{r e c}}{X_{S P V}^{r e c}}\right)^{2}(p-\underline{p})(1-p+\underline{p})-2 r\left(\frac{r X_{B}^{r e c}}{X_{S P V}^{r e c}}\right) \underline{p}(p-\underline{p})+\operatorname{var}\left[\tilde{R}_{2}\right]
\end{gathered}
$$

and the individual investor's project demand is:

$$
X_{I}^{r e c, 2}=\frac{\underline{p} r+(p-\underline{p}) \frac{r X_{B}^{r e c}}{X_{S P V}^{r e c}}+\mathbb{E}\left[\tilde{R}_{2}\right]-1}{2 \lambda \operatorname{var}\left[\tilde{R}_{S P V}^{r e c, 2}\right]}
$$

Bank investment. Consider the case with recourse to bank capital first. If it holds that $r X_{S P V}^{r e c, 1}<$ $X_{B}^{r e c}\left(r+R_{L}-(1-k) R_{D}\right.$, the BHC's objective is given by:

$$
\begin{gathered}
\mathbb{E} \Pi_{B}=\underline{p} X_{B}\left(r+\mathbb{E}\left[\tilde{R}_{2}\right]-(1-k) R_{D}\right)+(p-\underline{p})\left(X_{B}\left(r+\mathbb{E}\left[\tilde{R}_{2}\right]-(1-k) R_{D}\right)-r X_{S P V}^{r e c, 1}\right)+ \\
(1-p) m\left(R_{H}-(1-k) R_{D}\right)+s_{S P V}^{r e c, 1} X_{S P V}^{r e c, 1}-\delta k X_{B}-c\left(X_{B}\right)^{2}
\end{gathered}
$$

which results in the same first order condition for $X_{B}$ as under no recourse policy and thus the bank lending is chosen at the level $X_{B}^{r e c, 1}=X_{B}^{n r}$, equal to:

$$
X_{B}^{n r}=\frac{p\left(r+\mathbb{E}\left[\tilde{R}_{2}\right]-(1-k) R_{D}\right)+(1-p) m\left(R_{H}-(1-k) R_{D}\right)-\delta k}{2 c}
$$


If $\left(r+R_{L}-(1-k) R_{D}\right) X_{B}^{r e c, 1}<r X_{S P V}^{r e c, 1} \leq r X_{B}^{r e c, 2}$, the guarantees provide a recourse to deposit insurance but full repayments are still feasible. The BHC's defaults if the state $(r, 0)$ at the middle date and if $R_{L}$ at the end of the period are realized. The bank investment level maximizing the expected end-of-period profits is given by:

$$
X_{B}^{r e c, 2}=\frac{\underline{p}(1-m)\left(r+R_{L}-(1-k) R_{D}\right)+m\left(p r+R_{H}-(1-k) R_{D}\right)-\delta k}{2 c}
$$

Finally, when only partial guarantee repayments are feasible under the recourse to deposit insurance $\left(r X_{S P V}^{r e c, 1}>r X_{B}^{r e c, 2}\right)$, the new expected profit is:

$$
\begin{gathered}
\mathbb{E}_{B}=\underline{p} X_{B}\left(r+\mathbb{E}\left[\tilde{R}_{2}\right]-(1-k) R_{D}\right)+(p-\underline{p}) m X_{B}\left(R_{H}-(1-k) R_{D}\right)+ \\
(1-p) m X_{B}\left(R_{H}-(1-k) R_{D}\right)+s_{S P V}^{r e c} X_{S P V}^{r e c}-\delta k X_{B}-c\left(X_{B}\right)^{2}
\end{gathered}
$$

Additionally, the income from SPV intermediation is now a function of the bank investment. The optimal bank lending $X_{B}^{r e c, 3}$ thus satisfies the following first order condition:

$$
\underline{p}\left(r+\mathbb{E}\left[\tilde{R}_{2}\right]-(1-k) R_{D}\right)+(1-\underline{p}) m\left(R_{H}-(1-k) R_{D}\right)+\frac{d\left(s_{S P V}^{r e c} X_{S P V}^{r e c}\right)}{d X_{B}^{r e c, 3}}=2 c X_{B}^{r e c, 3}+\delta k
$$

Equilibria. In the presence of implicit guarantees the possible equilibrium allocations are following:

1. Recourse to bank capital. The guarantees provide a recourse to bank capital whenever:

$$
\begin{gathered}
r X_{S P V}^{r e c, 1} \leq\left(r+R_{L}-(1-k) R_{D}\right) X_{B}^{r e c, 1} \Leftrightarrow \\
\frac{r\left(p r+\mathbb{E}\left[\tilde{R}_{2}\right]-1\right)}{2 \lambda \operatorname{var}\left[\tilde{R}_{S P V}^{r e c, 1}\right]}< \\
\frac{p r+m R_{H}+(1-m) p R_{L}-(p+(1-p) m)(1-k) R_{D}-\delta k}{2 c}\left(r+R_{L}-(1-k) R_{D}\right)
\end{gathered}
$$

From Assumption 2 and from the fact that $\operatorname{var}\left[\tilde{R}_{S P V}^{r e c, 1}\right]<\operatorname{var}\left[\tilde{R}_{S P V}\right]$, a sufficient condition for (56) NOT to hold is therefore:

$$
\begin{gathered}
r\left((1-p)(1-m) R_{L}-R_{D}+\delta k+\left(p+(1-p) m(1-k) R_{D}\right)\right)> \\
\left(R_{L}-(1-k) R_{D}\right)\left(p r+m R_{H}+(1-m) p R_{L}-(p+(1-p) m)(1-k) R_{D}-\delta k\right)
\end{gathered}
$$

The maximum value of the RHS of the above expression is obtained for $R_{L}=(1-k) R_{D}$ and equal zero. It can be easily verified that for any $R_{L}<(1-k) R_{D}$ (Assumption 1 ) the above 
inequality always holds: the LHS is always positive and RHS is always negative. As a result, the recourse to bank capital is never feasible in equilibrium.

2. Recourse to deposit insurance with full repayments. The guarantees provide a recourse to bank deposit insurance, and full repayments are still possible if:

$$
\begin{gathered}
r X_{S P V}^{r e c, 1} \leq r X_{B}^{r e c, 2} \Leftrightarrow \\
\frac{p r+\mathbb{E}\left[\tilde{R}_{2}\right]-1}{2 \lambda \operatorname{var}\left[\tilde{R}_{S P V}^{r e c, 1}\right]} \leq \frac{\underline{p}(1-m)\left(r+R_{L}-(1-k) R_{D}\right)+m\left(p r+R_{H}-(1-k) R_{D}\right)-\delta k}{2 c} \Leftrightarrow \\
k \leq \frac{\underline{p}(1-m)\left(r+R_{L}-R_{D}\right)+m\left(p r+R_{H}-R_{D}\right)-B}{\delta-(\underline{p}(1-s)+s) R_{D}}=\overline{\bar{k}}
\end{gathered} \Leftrightarrow
$$

where

$$
B=\frac{c\left(p R+\mathbb{E}\left[R_{2}\right]-1\right)}{\lambda \operatorname{var}\left[\tilde{R}_{S P V}^{r e c, 1}\right]}
$$

Under full repayments, the equilibrium allocation is the pair $\left(X_{B}^{r e c, 2}, X_{I}^{r e c, 1}\right)$.

3. Recourse to deposit insurance with partial repayments. For $k>\overline{\bar{k}}$ guarantees are only partially repaid. The equilibrium bank investment and the SPV project issuance $\left(X_{B}^{r e c, 3}, X_{I}^{r e c, 2}\right)$ are given by the following conditions:

- The representative investor's SPV project demand is equal:

$$
X_{I}^{r e c, 2}=\frac{\underline{p r}+(p-\underline{p}) \frac{r X_{B}^{r e c, 3}}{X_{S P V}^{r e c}}+\mathbb{E}\left[\tilde{R}_{2}\right]-1}{2 \lambda \operatorname{var}\left[\tilde{R}_{S P V}^{r e c, 2}\right]}
$$

- The representative BHC's bank investment maximizes:

$$
\begin{gathered}
\max _{X_{B}}\left[\underline{p} X_{B}\left(r+\mathbb{E}\left[\tilde{R}_{2}\right]-(1-k) R_{D}\right)+(p-\underline{p}) m X_{B}\left(R_{H}-(1-k) R_{D}\right)+\right. \\
\left.(1-p) m X_{B}\left(R_{H}-(1-k) R_{D}\right)+s_{S P V}^{r e c} X_{S P V}^{r e c}-\delta k X_{B}-c\left(X_{B}\right)^{2}\right]
\end{gathered}
$$

- In equilibrium $X_{I}^{r e c, 2}=X_{S P V}^{r e c}$. 


\section{Tables and Figures}

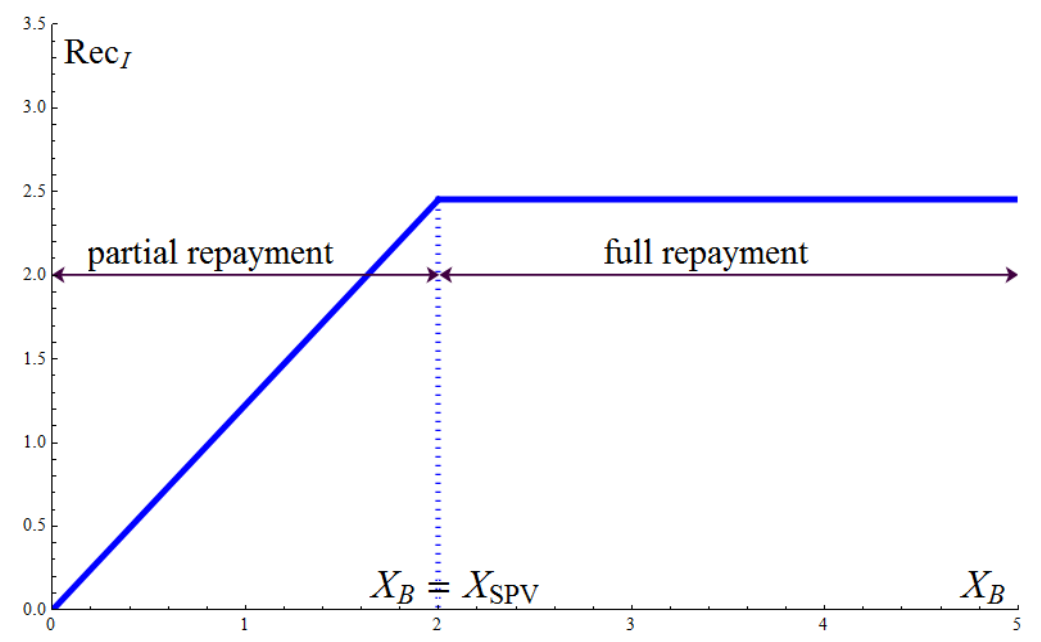

Figure 2: Implicit guarantees to the institutional investor: value as a function of the bank investment size.

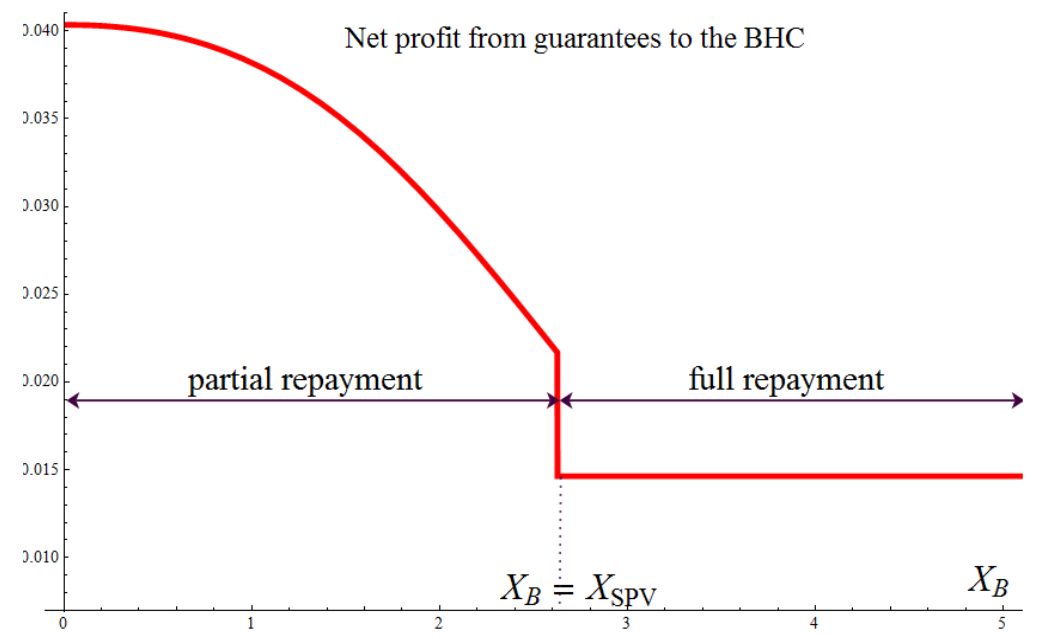

Figure 3: Profits from implicit guarantees to the sponsoring BHC: value as a function of the bank investment size. 


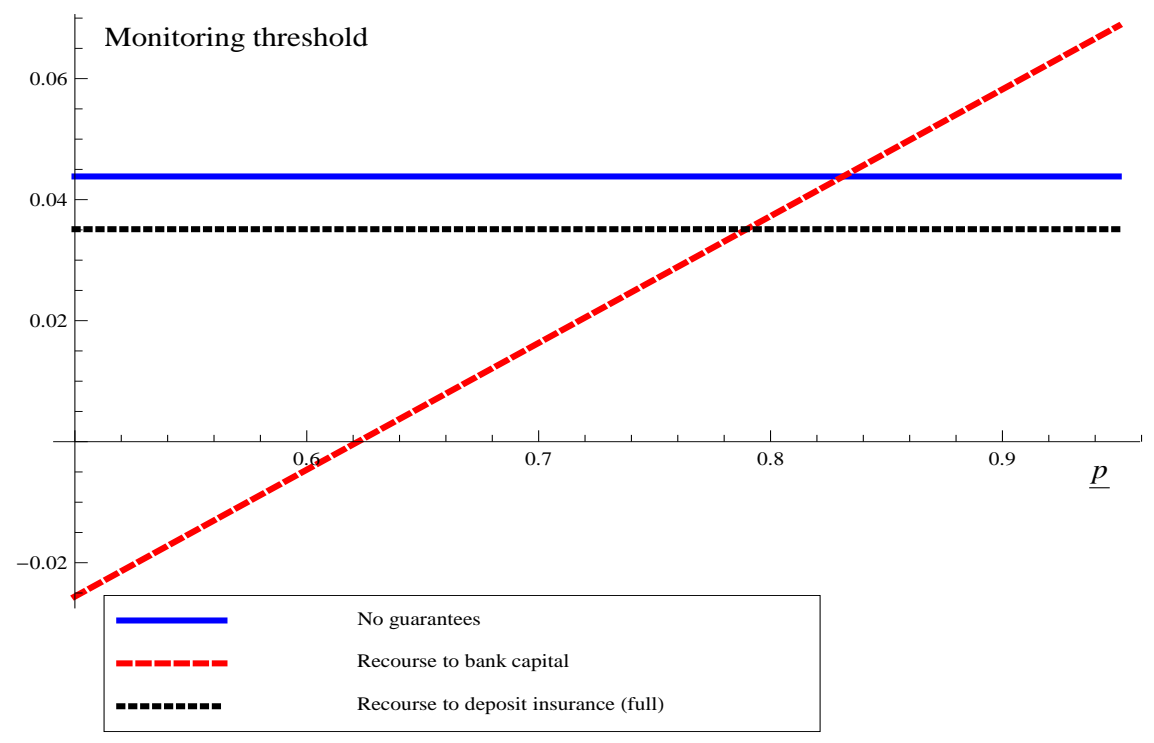

(a) Bank monitoring thresholds for low SPV project demand.

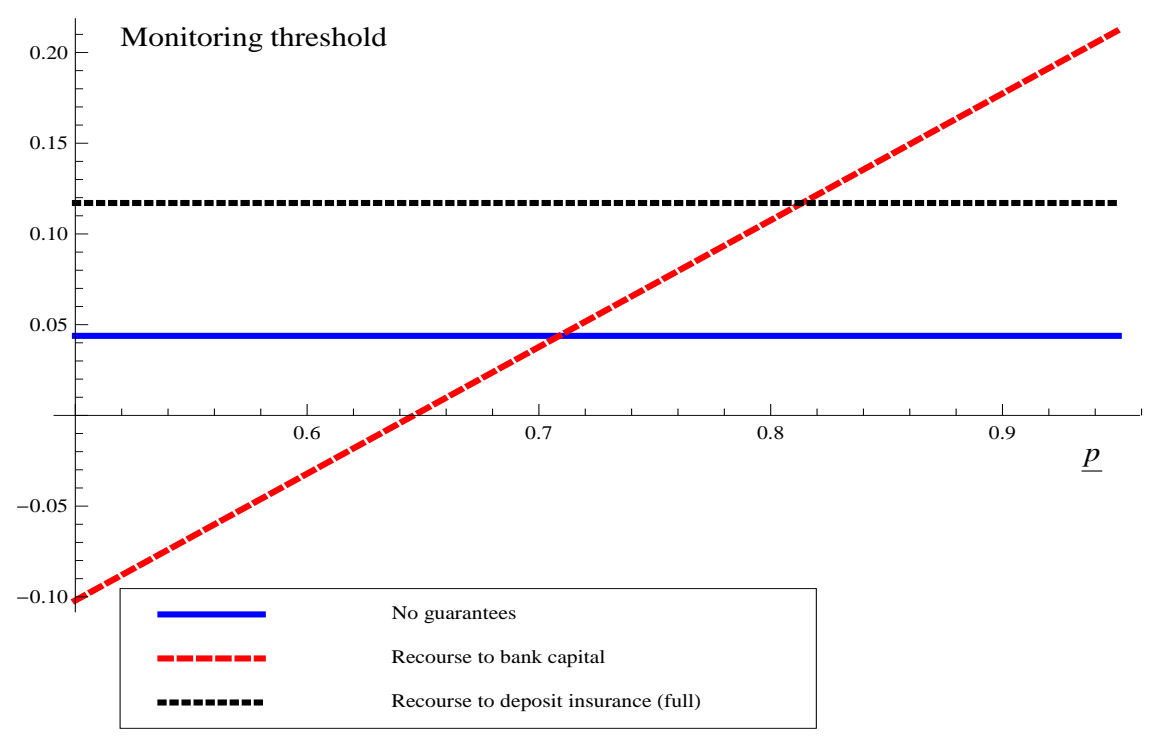

(b) Bank monitoring thresholds for high SPV project demand.

Figure 4: Bank monitoring decisions.

This figure shows the monitoring thresholds for the bank project as a function of the SPV project success probability $\underline{p}$ : in the absence of guarantees (solid line), under recourse to bank capital (dashed line) and under recourse to deposit insurance when full guarantee repayments are feasible (dotted line). The upper panel shows the monitoring thresholds when the SPV project demand is low $(\lambda=1)$, the bottom panel presents the thresholds for high levels of the SPV project demand $(\lambda=0.3)$. Parameter values: $p=0.95, \underline{p}_{H}=0.94, \underline{p}_{L}=0.85, R=1.2, R_{D}=1, X_{B}=1.2, \beta=0.95$, $s=0.1, k=0.08, c=0.2, \delta=1.09, q=0.8$ 


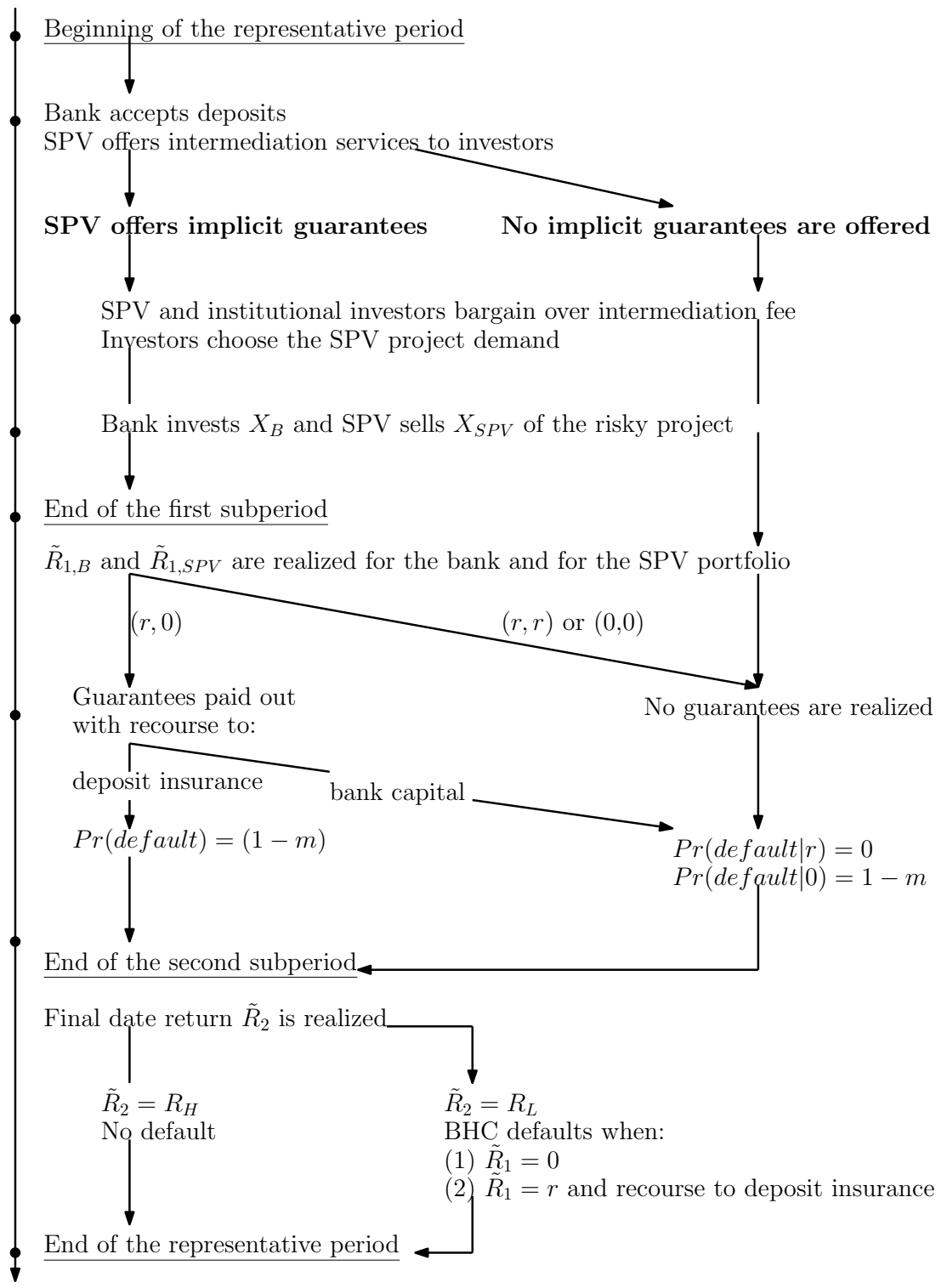

Figure 5: Model with two-stage returns: timeline in the representative period. 


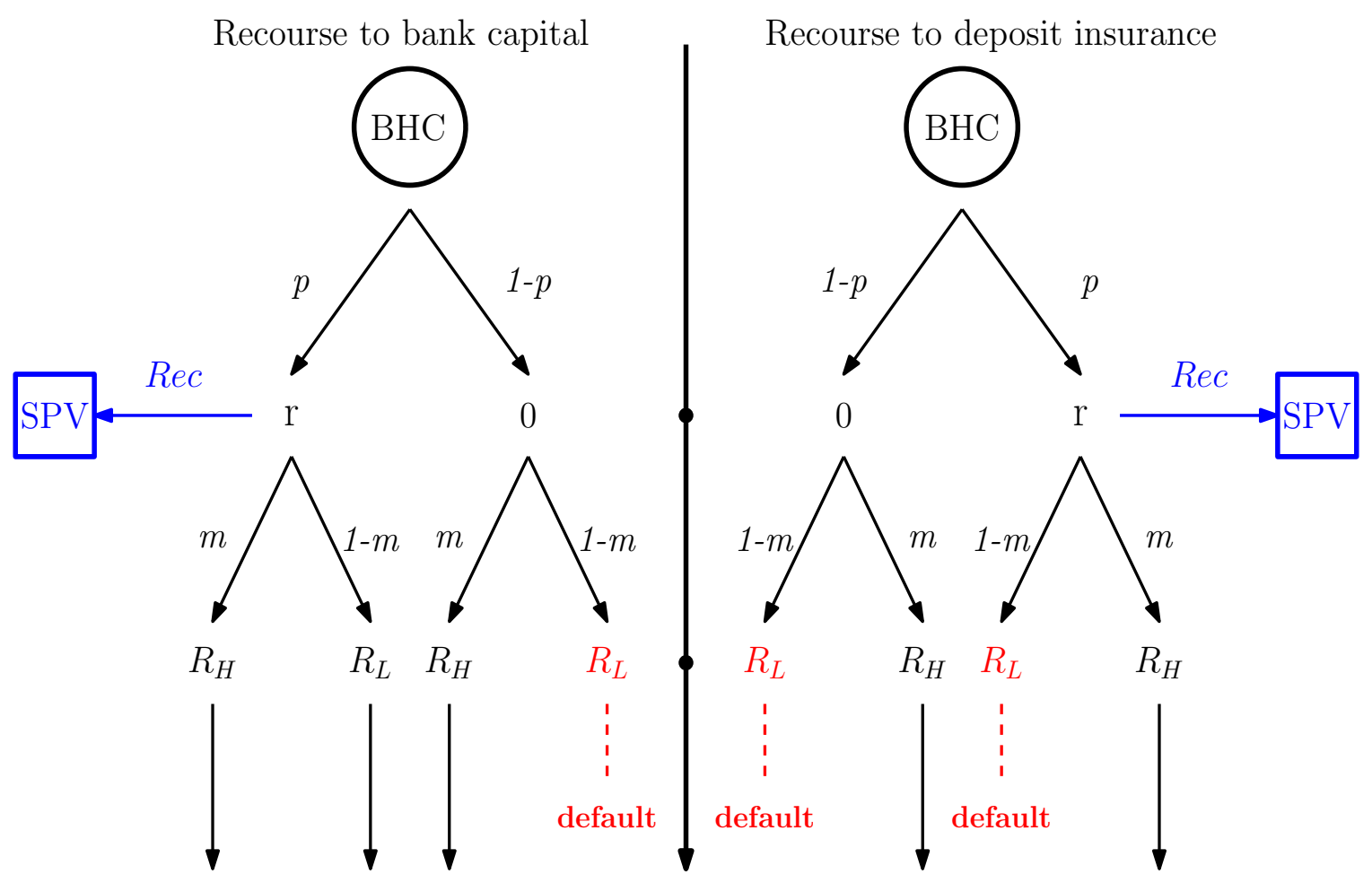

Figure 6: Model with two-stage returns: end of period outcomes. 

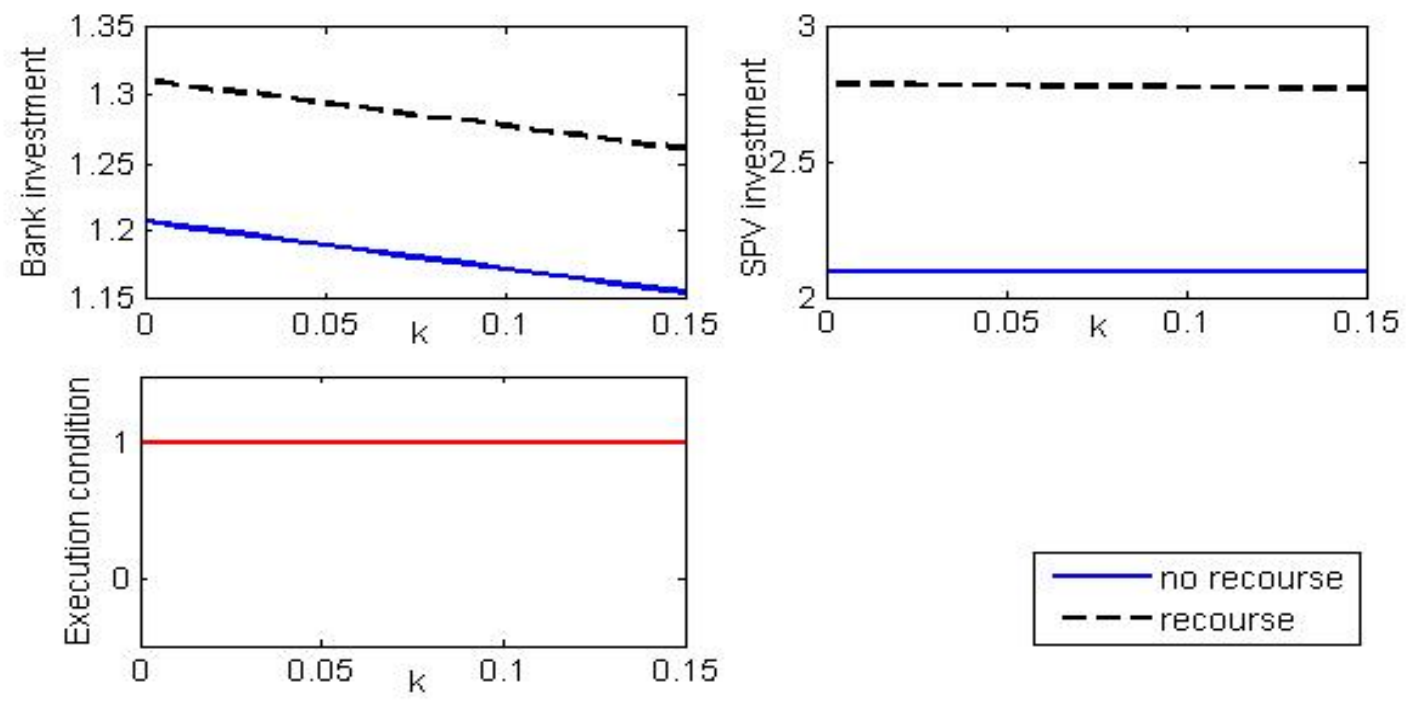

no recourse

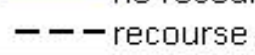

Figure 7: (Model with two-stage returns) Investment and ex post execution condition for different values of the capital requirement $k$. Parameter values: $r=0.3, R_{H}=1.01$, $R_{L}=0.8, p=0.8, \underline{p}=0.7, s=0.95, \beta=0.95, c=0.1, \lambda=2.1, \gamma=0.5, \delta=1.06$.
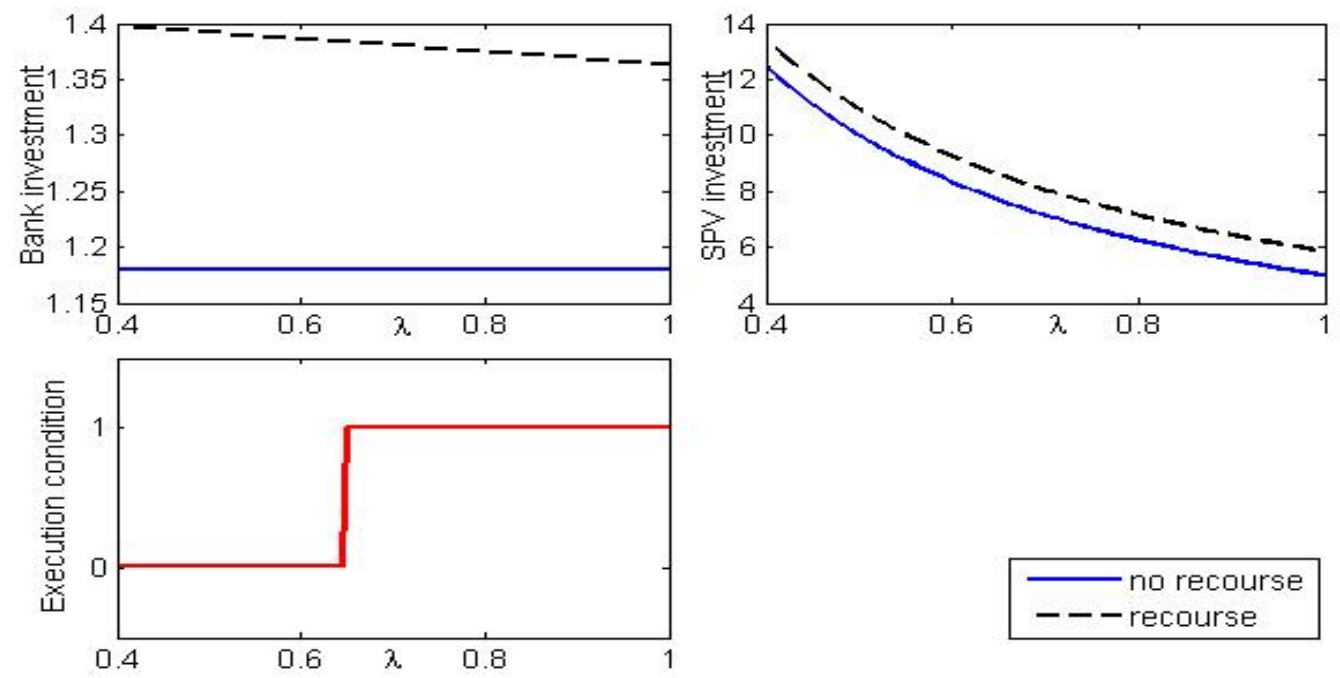

Figure 8: (Model with two-stage returns) Investment and ex post execution condition for different values of parameter $\lambda$. Parameter values: $r=0.3, R_{H}=1.01, R_{L}=0.8$, $p=0.8, \underline{p}=0.7, s=0.95, \beta=0.95, c=0.1, k=0.1, \gamma=0.5, \delta=1.06$. 

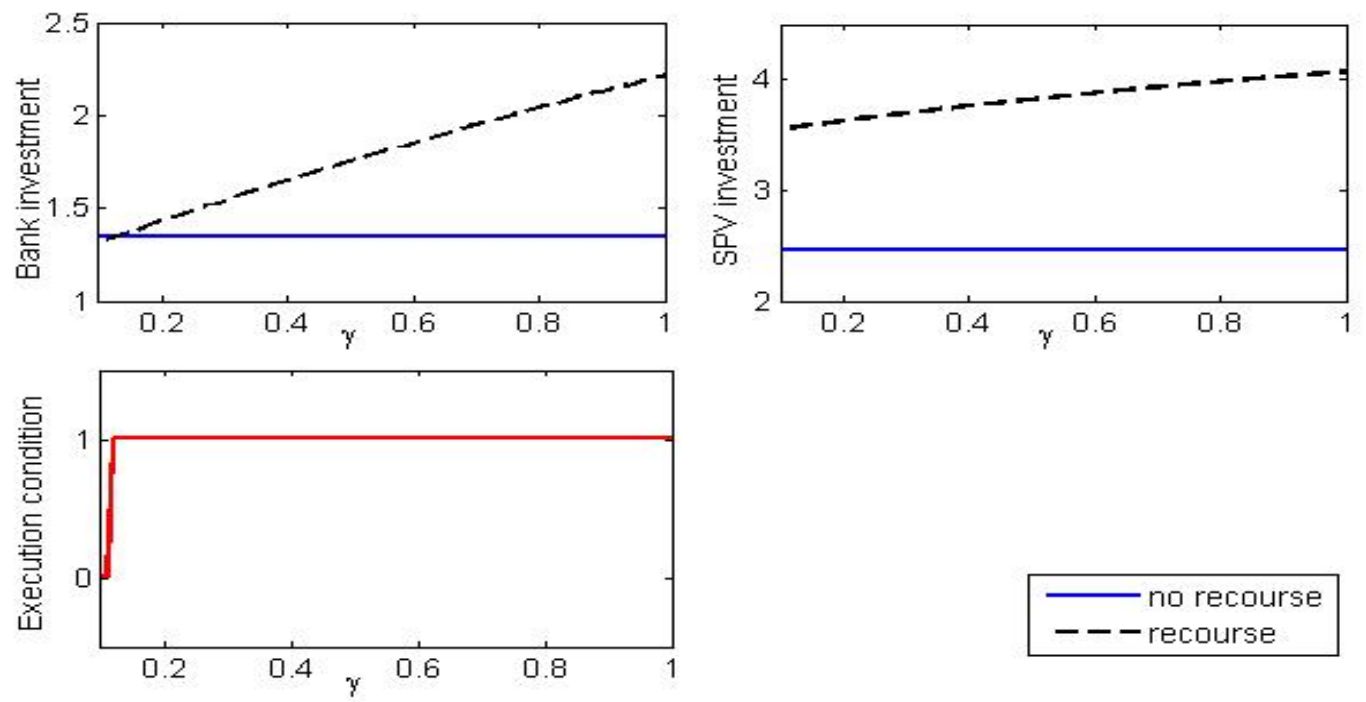

no recourse -- recourse

Figure 9: (Model with two-stage returns) Investment and ex post execution condition for different values of parameter $\gamma$. Parameter values: $r=0.3, R_{H}=1.01, R_{L}=0.8$, $p=0.9, \underline{p}=0.8, s=0.95, \beta=0.95, c=0.1, k=0.1, \lambda=2.1, \delta=1.06$. 